\title{
Optimal Alliance Strategy and Its Impact in a Closed-Loop Supply Chain by considering Greenness and Service Effort
}

\author{
Wei Shi, ${ }^{1,2}$ Haoran Chen, ${ }^{1}$ Xuemei Zhang ${ }^{10},{ }^{1,2}$ and Chenhao $\mathrm{Ma}^{1}$ \\ ${ }^{1}$ Business School, Fuyang Normal University, Fuyang 236037, Anhui, China \\ ${ }^{2}$ Anhui Provincial Key Laboratory of Regional Logistics Planning and Modern Logistics Engineering, Fuyang Normal University, \\ Fuyang 236037, Anhui, China \\ Correspondence should be addressed to Xuemei Zhang; xmz@mail.ustc.edu.cn
}

Received 17 December 2020; Revised 27 January 2021; Accepted 3 February 2021; Published 24 February 2021

Academic Editor: Josefa Mula

Copyright (c) 2021 Wei Shi et al. This is an open access article distributed under the Creative Commons Attribution License, which permits unrestricted use, distribution, and reproduction in any medium, provided the original work is properly cited.

\begin{abstract}
This paper handles Stackelberg game models in light of different alliance strategies in a closed-loop supply chain (CLSC) consisting of a manufacturer, a retailer, and a third-party recycler. In this CLSC, four scenarios are examined: the decentralized case, the manufacturer and the retailer forming an alliance, the manufacturer and the third-party recycler forming an alliance, and the centralized case. And in these Stackelberg game models, a comparison between four alliance strategies is analyzed by considering greenness and service effort. The effect of alliance strategy on the decisions of the CLSC system, consumer, environment, and society is also investigated. The main objective is to find out the optimal price, greenness level, and service effort to maximize the CLSC members' profits and give the optimal alliance strategy by using theoretical analysis. It is found that the alliance strategy improves the operation efficiency of the CLSC, and it also benefits consumers, the environment, and society. The MR alliance strategy is more effective than the MT alliance strategy, but it cannot achieve the efficiency of a centralized scenario. Finally, numerical examples are illustrated to justify the feasibility and practicability of the proposed models in reality.
\end{abstract}

\section{Introduction}

With the development of the economy, the environmental issue is widely concerned to sustain human civilization, and the public's awareness of environmental protection is also increasing [1, 2]. Due to the increasing environmental pressure, more and more enterprises engage in recycling used products, resulting in a closed-loop supply chain (CLSC) [3, 4]. For example, Huawei, Gree, HP, and Xerox are actively exploring the recycling and remanufacturing of used products $[5,6]$. The recycling and remanufacturing of used products can not only reduce the average production cost of enterprises but also help enterprises to establish a brand image and cultivate customer loyalty [7]. Recycling is widely used in environmental protection, and more and more enterprises are engaged in the industry of recycling [8].

According to a global survey by Accenture, more than $80 \%$ of respondents will consider products with green and environmental attributes when they make purchase decisions. Consumers also pay attention to environmentally friendly products $[9,10]$. The introduction of consumer green preference into the closed-loop supply chain is of great practical significance for improving the level of closed-loop supply chain management. Influenced by consumers' preference for green products, many enterprises begin to control emission costs and invest in green products' research and development (R\&D) to enhance their competitiveness $[11,12]$.

In addition, retailers provide service effort to attract more consumers to pay attention to green products $[13,14]$. The service effort consisting of environmental advertising or promotion of environmental education provided by retailers can help consumers better understand green products, which can promote the sales and recycling of green products [15]. For example, Walmart has developed a green marketing plan for its suppliers that allows companies, including manufacturers and retailers, to benefit financially from environmental responsibility in their production and 
operations [16]. For retailers, how to balance the relationship between sales revenue and service costs is critical to ensure profitability.

In order to reduce the cost of green product $\mathrm{R} \& \mathrm{D}$ and service efforts, CLSC members often form alliances to improve their competitiveness [3,17-20]. In reality, we can find various alliance structures in CLSC. In some cases, manufacturers and retailers or third-party recyclers form a strategic alliance. For example, the manufacturer Haier has worked with big retailers such as Suning and Gome to improve decision-making efficiency and reduce R\&D costs [21]. Nike has formed an alliance with the third-party nonprofit structure "National Recycling Coalition" for recycling products [22]. In practice, manufacturers cooperate with retailers and third-party recyclers in selling and collecting markets. For example, the big US carmakers Ford and GM have been working with specialist third-party recyclers to recycle used products, and Xerox and Eastman Kodak are working with downstream retailers to sell products and recycle used products [17]. Therefore, more and more attention has been paid to the alliance strategies. However, the effect of alliance strategies on product pricing, greenness, and service effort decisions in the CLSC is still not investigated in depth, such as whether the decision-making of CLSC will be changed? Which is the best alliance strategy? In this study, the impact of different alliance strategies on the decisions of CLSC, consumers, the environment, and society will be investigated.

More specifically, by considering the greenness and service effort, we incorporate the different alliance strategies into a typical CLSC consisting of a manufacturer (M), a retailer $(R)$, and a third-party recycler $(T)$. Four scenarios are examined: (1) the decentralized case where the three CLSC members make independent decisions $(D) ;(2) M$ and $R$ forming an alliance (MR); (3) $M$ and $T$ forming an alliance (MT); (4) the centralized case where a central planner makes integrated decisions for the three CLSC members $(C)$.

This research attempts to address the following three questions:

(1) How to derive the equilibrium decisions of price, greenness level, service effort, and recycling rate for the CLSC with different alliance strategies under the $D, \mathrm{MR}, \mathrm{MT}$, and $C$ models?

(2) What is the effect of the alliance strategy on the performance of the CLSC, consumer, environment, and society?

(3) What is the optimal alliance strategy to heighten the CLSC operation efficiency, consumer surplus, environmental improvement, and social welfare?

The remainder of this paper is organized as follows. A brief review is presented in Section 2. Section 3 describes the problem and model assumptions. In Section 4, the equilibrium results of the four models are derived, and a comparative analysis for the optimal results of the four models is given. Numerical analysis is illustrated in Section 5. Managerial insights of the proposed models are given in Section 6. Section 7 concludes the paper.

\section{Literature Review}

In a CLSC, many analyses have been carried out from various perspectives, such as product recycling and remanufacturing, R\&D, and channel selections. Based on the research questions in this paper, we focus our review on sustainable supply chain management, $R \& D$ in the supply chain, service effort in the supply chain, and the alliance of supply chain members.

2.1. Sustainable Supply Chain Management. With the aggravation of environmental pollution, sustainable supply chain management has been widely concerned [23-27]. Das and Rao Posinasetti [28] integrate environmental concerns in a closed-loop supply chain model to improve overall SC performance. Gao et al. [29] examine the influence of different channel power structures on the optimal decisions and performance of a closed-loop supply chain (CLSC) from the perspective of profit and environment. Modak et al. [30] propose a two-stage competitive CLSC and coordination model to improve environmental and economic aspects of sustainability. Taleizadeh et al. [31] find that by means of the proposed model, the application of Stackelberg-Bertrand behavior in the field of airport congestion pricing will rebound to a more profitable strategy in contrast with the other three represented methods. Wang et al. [32] investigate the relationship between profitability and environmental goals in a reverse supply chain. The main finding is that while they often conflict, they may align under certain conditions. Johari and Hosseini-Motlagh [33] propose an analytical coordination model to cover all three dimensions of sustainability. They measure social welfare by the sum of firms' profits and consumer surplus. Wang et al. [34] incorporate the environmental benefit when calculating social welfare and find the conditions under which confliction exists between profitability and environmental benefit/social welfare. These studies mainly focus on the green product design in the supply chain, but limited research has considered the impact of alliance strategy and retailers' service effort. In reality, manufacturers usually cooperate with their CLSC members to sell products and recycle used products. The different alliance strategies will affect the decision-making behavior of CLSC members.

2.2. RઐD in Supply Chain. Many manufacturers carry out $R \& D$ to increase the greenness of products, which have become an important factor affecting consumers' purchasing decisions $[35,36]$. Zhang et al. [37] show that the technologysharing strategy chosen by the R\&D teams is closely related to the sharable coefficient of technology and also closely related to the benefits obtained through free-riding. Chen et al. [11] explore firms' green $\mathrm{R} \& \mathrm{D}$ cooperation behavior in a twoechelon supply chain in which a manufacturer and a retailer first cooperate to invest green R\&D and then organize production according to a wholesale price contract. Zhang and Hong [38] consider that the manufacturer makes R\&D investment to improve the product quality and reduce the 
production cost. Vendrell-Herrero et al. [39] find that customer and logistics IT processes are positively linked to higher levels of PSI and that, as hypothesized, service R\&D team structure moderates this relationship. Dai et al. [40] investigate a supply chain consisting of an OEM and a CM and establish a three-dimensional discrete dynamic model with time delay by considering R\&D efforts and marketing level. Huang et al. [41] propose a collaborative R\&D model based on customers' selection behavior to study the collaborative $\mathrm{R} \& \mathrm{D}$ policy and pricing policy of the supply chain. The abovementioned studies indicate that $\mathrm{R} \& \mathrm{D}$ has a significant influence on the performance of the supply chain. Limited research focuses on green $R \& D$ and the impact of alliance strategy on R\&D in the supply chain. It is valuable to explore the green $R \& D$ problem in the supply chain.

2.3. Service Effort in Supply Chain. Many retailers put in service effort to attract more consumers to buy products $[42,43]$. Basiri and Heydari [44] investigated green supply chain coordination issues for substitutable products with retail price, greening level, and sales' effort-dependent demand for a two-stage supply chain. Liu et al. [45] explore information sharing in an e-tailing supply chain for fresh produce with freshness-keeping effort and value-added service. They find that information sharing may benefit the e-tailer and that the e-tailer chooses to share information voluntarily when the freshness elasticity is above a certain threshold. By analyzing the pricing, service, recycling decisions, and the profit of the supply chain members in different remanufacturing modes, Zhao et al. [13] show that the FR remanufacturing mode not only promotes the retailer to improve the product service level but also enables the third-party to improve the recovery rate. Li et al. [46] investigate the influence of the showrooming effect on firms' pricing and service effort in a dual-channel supply chain and find that the greater the showrooming effect, the higher profits firms will obtain using the ex-post service effort strategy. Cao et al. [47] consider that the greenness level is jointly determined by the greening efforts of both the cooperative and enterprise and design a cost-sharing contract and a buyback contract to coordinate the greening effort decisions. It is worth noting that the service effort plays an important role in the supply chain, but limited research has considered supply chain members forming an alliance to provide service effort. It is worth exploring how the CLSC alliances provide service effort.

2.4. Alliance of Supply Chain Members. The alliance strategy of supply chain members has been widely concerned by scholars [47, 48]. Wu et al. [49] investigate a sustainable power supply chain that consists of a traditional energy power generation firm (TEF), a renewable energy power generation firm (REF), and a downstream power distributor (PD) by considering a technology-driven alliance. Zheng et al. [3] use cooperative game approaches to coordinating a three-echelon closed-loop supply chain with fairness concerns and put forward an appropriate profit allocation scheme. Lin et al. [50] analyze firms' eco-innovation investment strategy in a supply chain with a buyer and two suppliers in the presence of knowledge spillovers and technology gaps among suppliers and derive the innovation alliance strategy. Lechler et al. [51] explore from an extended agency theory perspective how companies collaborate within assessment sharing strategic alliances to manage suppliers with respect to sustainability and to reveal the resultant effects on the management of suppliers within multitier supply chains. Taleizadeh et al. [52] explore the optimal pricing and alliance strategy when a new vendor enters the market and find that having the alliance strategy need not improve the supply chain performance. Li et al. [53] investigate which alliance strategy is more conducive to maximizing economic and social benefits. These aforementioned papers all highlighted that alliance strategy plays a significant role in the supply chain, but limited research focuses on the impact of alliance strategy on greenness level and service effort in the CLSC. In this paper, we attempt to explore the effect of alliance strategy on the environmental, economic, and operational management of CLSC.

More specifically, considering consumer's green preference, manufacturer's green $\mathrm{R} \& \mathrm{D}$, and retailer's service effort, we introduce three alliance strategies of CLSC members and structure four models: no alliance, $M$ and $R$ alliance, $M$ and $T$ alliance, and $M, \mathrm{R}$, and $T$ alliance. We first derive the equilibrium results under the four models and then analyze the impact of alliance strategy on price, service effort, recycling rate, greenness level, CLSC member profit, consumer surplus, environmental improvement, and social welfare. Finally, the efficiency of the alliance strategy is verified, and the optimal alliance strategy is given.

The main contributions of this paper are as follows:

(1) Exploring whether the manufacturer forms alliances with the retailer or third-party recycler and the decision-making of price, greenness level, service effort, and recycling rate in a CLSC is investigated under different alliance strategies

(2) Structuring four dynamic game models to analyze the effect of alliance strategy on decisions and profit of a CLSC, and the efficiency of alliance strategy to alleviate double margination is explored

(3) Investigating the impact of alliance strategy on the consumer surplus, environmental improvement, and social welfare, and an optimal alliance strategy that makes the interest of supply chain member, consumer, environment, and society consistent is proposed

\section{Problem Description and Model Assumptions}

We consider a closed-loop supply chain consisting of $M, R$, and $T$, and they play a Stackelberg dynamic game. In a decentralized dynamic model, $M$ produces new products and remanufactures used products collected by $T$ and then wholesales new and remanufactured products to $R$. $R$ retails the new and remanufactured products to consumers. In the 
CLSC, $M$ invests in green product R\&D, $R$ offers service effort to increase consumer demand, and $T$ invests cost to recycle the used products. $M$ is modeled as the leader, and $R$ and $T$ are the followers.

To derive the optimal alliance strategy and its impact on the CLSC, we need to examine all possible alliance strategies. Since $R$ has no direct contact with $T$, it will not form an alliance. Therefore, four models are considered as shown in Figure 1: a decentralized model $D$ where each member makes its own decisions, an alliance model MR where $M$ and $R$ form an alliance to make centralized decisions within the alliance, an alliance model MT where $M$ and $T$ form an alliance to make centralized decisions with the alliance, and a centralized alliance model $C$ where $M, R$, and $T$ make centralized decisions.

This paper only considers a single product, i.e., a new product or a remanufactured product. New and remanufactured products coexist in the same market, the new and remanufactured products are homogeneous, and a consumer can only own one product at the same time [54]. In the reverse distribution, to keep the models concise and to simplify analyses, following Shi et al. [20] and $\mathrm{Wu}$ and Zhou [55], $T$ pays consumers $A$ for each unit of used products, which is assumed to be zero. Based on the problem description, we employ the symbols and notations given in Table 1 throughout this paper.

To make the analysis tractable, we introduce the following assumptions about consumer preference, cost structure, environmental improvement, and social welfare in this research.

(i) Consumer Preference. Market demand is affected by price, green level, and service effort level. It is assumed that market demand is a linear function of them, i.e., $D=Q-\alpha p+\beta e+\gamma s[11,46]$. In the market demand function, we assume that $Q>\alpha p$ [29]. Consumer surplus for new and remanufactured products in a CLSC can be calculated as CS =

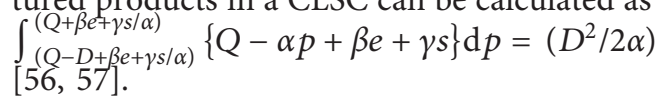

(ii) Cost Structure. Due to the recycling of used parts and components, producing a remanufactured product is cheaper than producing a new product, i.e., $c_{n}>c_{r}>0[13,26]$. Let $\Delta=c_{n}-c_{r}$ denote marginal cost savings from remanufacturing. To ensure that $M$ is profitable, we assume that $\Delta>b>0$ and $p>c_{n}$ [20]. Green R\&D investment cost function is assumed to be $(1 / 2) c_{g} e^{2}$ [58], service effort cost function is assumed to be $(1 / 2) c_{s} s^{2}$ [46], and T's recycling cost function is assumed to be $c_{R} \tau^{2}(0<\tau<1)[20,56]$. To ensure $Q>\alpha p, p>c_{n}$ and $\tau \in(0,1)$, we assume $c_{R}>\max \left\{\left(\alpha \Delta^{2} / 2\right)\right.$, $\left.\left(\alpha c_{g} c_{s} \Delta\left(Q-\alpha c_{n}+\alpha \Delta\right) / 2\left(2 \alpha c_{g} c_{s}-c_{s} \beta^{2}-c_{g} \gamma^{2}\right)\right)\right\}$ and $\alpha c_{g} c_{s}>c_{s} \beta^{2}+c_{g} \gamma^{2}[20]$.

(iii) Environmental Improvement. In the CLSC, the total carbon emission reduction after the green $R \& D$ investment is assumed to be $e D$ [59]. And thus, the environmental improvement after green $\mathrm{R} \& \mathrm{D}$ investment is linearly increasing in its carbon emission reduction, which is formulated as $\mathrm{EI}=c_{e} e D$ $[11,26]$.

(iv) Social Welfare. Social welfare is composed of CLSC members' profits, consumer surplus, and environmental improvement. Thus, the social welfare can be calculated as $\mathrm{SW}=\prod_{m}+\prod_{r}+\prod_{t}+\mathrm{CS}+\mathrm{EI}$ $[11,59,60]$.

\section{Equilibrium Analysis}

In this part, we derive the equilibrium results for the four models, $D, M R, M T$, and $C$. In the following calculation process, for analytical purpose, we denote $\phi_{1}=Q-\alpha c_{n}$, $\phi_{2}=4 \alpha c_{g} c_{s}-c_{s} \beta^{2}-2 c_{g} \gamma^{2}$, and $\phi_{3}=2 \alpha c_{g} c_{s}-c_{s} \beta^{2}-c_{g} \gamma^{2}$, and according to the hypothesis, $\phi_{1}, \phi_{2}$, and $\phi_{3}$ are all positive.

4.1. The Decentralized Model (Model D). In the model $D, M$, $R$, and $T$ maximize their profit, respectively. The decision sequence is as follows: $M$ first determines greenness level $e^{D}$, wholesale price $w^{D}$, and transfer price $b^{D}$, then $R$ decides service level $s^{D}$ and retailer price $p^{D}$, and $T$ simultaneously decides recycling rate $\tau^{D}$. They play a dynamic Stackelberg game. The optimization model of profit maximization is formulated as

$$
\begin{aligned}
& \max _{e^{D}, w^{D}, b^{D}} \prod_{m}^{D}=\left(w^{D}-c_{n}+\left(\Delta-b^{D}\right) \tau^{D}\right)\left(Q-\alpha p^{D}+\beta e^{D}+\gamma s^{D}\right)-\frac{1}{2} c_{g} e^{D 2} \\
& \text { s.t. }\left\{\begin{array}{l}
\max \prod_{r}^{D}=\left(p^{D}-w^{D}\right)\left(Q-\alpha p^{D}+\beta e^{D}+\gamma s^{D}\right)-\frac{1}{2} c_{s} s^{D 2} \\
\max _{\tau^{D}} \prod_{t}^{D}=b^{D} \tau^{D}\left(Q-\alpha p^{D}+\beta e^{D}+\gamma s^{D}\right)-c_{R} \tau^{D 2} .
\end{array}\right.
\end{aligned}
$$



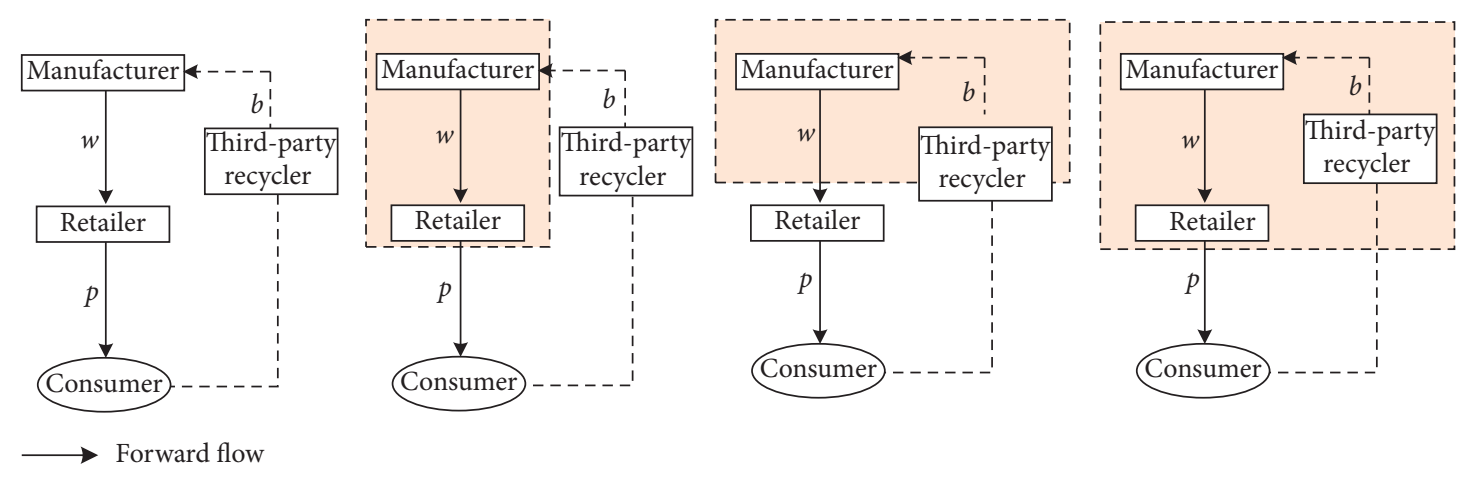

- - - Reverse flow

FIGURE 1: Supply chain structures of the CLSC.

TABle 1: Parameters and decision variables.

\begin{tabular}{lc}
\hline Notations & Definition \\
\hline$Q$ & Potential product market size \\
$\alpha$ & Price elasticity coefficient \\
$\beta$ & Green preference elasticity coefficient \\
$\gamma$ & Service elasticity coefficient \\
$c_{n} / c_{r}$ & Unit production cost of new/remanufactured products \\
$c_{g}$ & Green research and development cost coefficient \\
$c_{s}$ & Service effort cost coefficient \\
$\tau$ & Recycling rate of used products \\
$\Delta$ & Marginal cost saving from remanufacturing \\
$c_{R}$ & Recycling cost coefficient \\
$c_{e}$ & The cost of controlling environmental pollution caused by unit carbon emissions \\
$w$ & Unit wholesale price of new/remanufactured products \\
$b$ & Unit transfer price to $T$ from $\mathrm{M}$ \\
$p$ & Unit retail price of new/remanufactured products \\
$e$ & Greenness level \\
$s$ & Service effort level \\
$D$ & Market demand \\
$\prod_{i}^{j}$ & Profit of member $i$ in model $j, i \in\{m, r, m r, m t, c\}$ and $j \in\{D, M R, M T, C\}$ \\
$C S^{j}$ & Consumer surplus in mode $j, j \in\{D, M R, M T, C\}$ \\
$\mathrm{EI}^{j}$ & Environmental improvement in mode $j, j \in\{D, M R, M T, C\}$ \\
$\mathrm{SW}^{j}$ & Social welfare in model $j, j \in\{D, \mathrm{MR}, \mathrm{MT}, C\}$ \\
\hline
\end{tabular}

By using the reverse induction, we obtain the optimal results for the model $D$, which are described in Proposition 1.

Proposition 1. In the model $D$, the optimal results are given as $e^{D *}=4 \beta c_{s} c_{R} \phi_{1} /\left(4 c_{R} \phi_{2}-\alpha^{2} c_{g} c_{s} \Delta^{2}\right), s^{D *}=4 \gamma c_{R} c_{g} \phi_{1} /\left(4 c_{R}\right.$ $\left.\phi_{2}-\alpha^{2} c_{g} c_{s} \Delta^{2}\right), b^{D *}=\Delta / 2, w^{D *}=c_{n}+c_{g}\left(8 c_{R} c_{s} \alpha-c_{s} \alpha^{2} \Delta^{2}-\right.$ $\left.4 c_{R} \gamma^{2}\right) \phi_{1} /\left(\alpha\left(4 c_{R} \phi_{2}-\alpha^{2} c_{g} c_{s} \Delta^{2}\right)\right), \quad p^{D *}=c_{n}+c_{g}\left(12 c_{R} c_{s} \alpha-\right.$ $\left.c_{s} \alpha^{2} \Delta^{2}-4 c_{R} \gamma^{2}\right) \phi_{1} /\left(\alpha\left(4 c_{R} \phi_{2}-\alpha^{2} c_{g} c_{s} \Delta^{2}\right)\right)$, and $\tau^{D *}=\alpha c_{g} c_{s}$ $\Delta \phi_{1} /\left(4 c_{R} \phi_{2}-\alpha^{2} c_{g} c_{s} \Delta^{2}\right)$.

The proof is given in Appendix A.

And thus, the optimal demand and profit are shown as $D^{D *}=4 \alpha c_{R} c_{g} c_{s} \phi_{1} /\left(4 c_{R} \phi_{2}-\alpha^{2} c_{g} c_{s} \Delta^{2}\right), \quad \prod_{m}^{D *}=2 c_{R} c_{g} c_{s} \phi_{1}^{2} /$ $\left(4 c_{R} \phi_{2}-\alpha^{2} c_{g} c_{s} \Delta^{2}\right), \quad \prod_{r}^{D *}=8 c_{R}^{2} c_{g}^{2} c_{s}\left(2 \alpha c_{s}-\gamma^{2}\right) \phi_{1}^{2} /\left(4 c_{R} \phi_{2}-\right.$ $\left.\alpha^{2} c_{g} c_{s} \Delta^{2}\right)^{2}$, and $\prod_{t}^{D *}=\alpha^{2} c_{R} c_{g}^{2} c_{s}^{2} \Delta^{2} \phi_{1}^{2} /\left(4 c_{R} \phi_{2}-\alpha^{2} c_{g} c_{s} \Delta^{2}\right)^{2}$.
The optimal consumer surplus, environmental improvement, and social welfare are shown as

$$
\begin{aligned}
\mathrm{CS}^{D *} & =\frac{8 \alpha c_{R}^{2} c_{g}^{2} c_{s}^{2} \phi_{1}^{2}}{\left(4 c_{R} \phi_{2}-\alpha^{2} c_{g} c_{s} \Delta^{2}\right)^{2}}, \\
\mathrm{EI}^{D *} & =\frac{16 \beta c_{e} c_{s}^{2} c_{R}^{2} \alpha c_{g} \phi_{1}^{2}}{\left(4 c_{R} \phi_{2}-\alpha^{2} c_{g} c_{s} \Delta^{2}\right)^{2}}, \\
\mathrm{SW}^{D *} & =\prod_{m}^{D *}+\prod_{r}^{D *}+\prod_{t}^{D *}+\mathrm{CS}^{D *}+\mathrm{EI}^{D *} .
\end{aligned}
$$

4.2. $M$ and $R$ Form an Alliance (Model MR). In the model $\mathrm{MR}, M$ and $R$ form an alliance and are treated as a new 
decision-maker who decides greenness level $e^{\mathrm{MR}}$, service level $s^{\mathrm{MR}}$, retailer price $p^{\mathrm{MR}}$, and transfer price $b^{\mathrm{MR}}$. Subsequently, $T$ decides the recycling rate $\tau^{\mathrm{MR}}$. In this case, alliance MR and $T$ play a Stackelberg game. The alliance model is formulated as

$$
\begin{aligned}
& \max _{e^{\mathrm{MR}}, s^{\mathrm{MR}}, p^{\mathrm{MR}}, b^{\mathrm{MR}}} \prod_{m r}^{\mathrm{MR}}=\left(p^{\mathrm{MR}}-c_{n}+\left(\Delta-b^{\mathrm{MR}}\right) \tau^{\mathrm{MR}}\right)\left(\mathrm{Q}-\alpha p^{\mathrm{MR}}+\beta e^{\mathrm{MR}}+\gamma s^{\mathrm{MR}}\right)-\frac{1}{2} c_{e} e^{\mathrm{MR} 2}-\frac{1}{2} c_{s} s^{\mathrm{MR} 2} \\
& \text { s.t. } \quad \max _{\tau^{M R}} \prod_{t}^{\mathrm{MR}}=b \tau^{\mathrm{MR}}\left(\mathrm{Q}-\alpha p^{\mathrm{MR}}+\beta e^{\mathrm{MR}}+\gamma s^{\mathrm{MR}}\right)-C_{L} \tau^{\mathrm{MR} 2} .
\end{aligned}
$$

By using the reverse induction, we obtain the optimal results for the model MR, which are described in Proposition 2.

Proposition 2. In the model $M R$, the optimal results are given as $e^{M R *}=4 \beta c_{R} c_{s} \phi_{1} /\left(4 c_{R} \phi_{3}-\alpha^{2} c_{g} c_{s} \Delta^{2}\right), s^{M R *}=4 c_{R} c_{g}$ $\gamma \phi_{1} /\left(4 c_{R} \phi_{3}-\alpha^{2} c_{g} c_{s} \Delta^{2}\right), \quad p^{M R *}=c_{n}+c_{g} c_{s}\left(4 c_{R}-\alpha \Delta^{2}\right) \phi_{1} /$ $\left(4 c_{R} \phi_{3}-\alpha^{2} c_{g} c_{s} \Delta^{2}\right), \quad b^{M R *}=\Delta / 2$, and $\tau^{M R *}=\Delta \alpha c_{g} c_{s} \phi_{1} /$ $\left(4 c_{R} \phi_{3}-\alpha^{2} c_{g} c_{s} \Delta^{2}\right)$.

The proof is given in Appendix $B$.

And thus, the optimal demand and profit are shown as $D^{M R *}=4 \alpha c_{R} c_{g} c_{s} \phi_{1} /\left(4 c_{R} \phi_{3}-\alpha^{2} c_{g} c_{s} \Delta^{2}\right), \quad \prod_{m r}^{M R *}=2 c_{R} c_{g}$ $c_{s} \phi_{1}^{2} /\left(4 c_{R} \phi_{3}-\alpha^{2} c_{g} c_{s} \Delta^{2}\right)$, and $\prod_{t}^{M R *}=\Delta^{2} \alpha^{2} c_{R} c_{g}^{2} c_{s}^{2} \phi_{1}^{2} /$ $\left(4 c_{R} \phi_{3}-\alpha^{2} c_{g} c_{s} \Delta^{2}\right)^{2}$.

The optimal consumer surplus, environmental improvement, and social welfare are shown as

$$
\begin{aligned}
\mathrm{CS}^{\mathrm{MR} *} & =\frac{8 \alpha c_{R}^{2} c_{g}^{2} c_{s}^{2} \phi_{1}^{2}}{\left(4 c_{R} \phi_{3}-\alpha^{2} c_{g} c_{s} \Delta^{2}\right)^{2}} \\
\mathrm{EI}^{\mathrm{MR} *} & =\frac{16 c_{e} \beta c_{R}^{2} c_{s}^{2} \alpha c_{g} \phi_{1}^{2}}{\left(4 c_{R} \phi_{3}-\alpha^{2} c_{g} c_{s} \Delta^{2}\right)^{2}} \\
\mathrm{SW}^{\mathrm{MR} *} & =\prod_{m r}^{\mathrm{MR} *}+\prod_{t}^{\mathrm{MR} *}+\mathrm{CS}^{\mathrm{MR} *}+\mathrm{EI}^{\mathrm{MR} *}
\end{aligned}
$$

4.3. $M$ and T Form an Alliance (Model MT). In the model MT, $M$ and $T$ form an alliance and are treated as a new decision-maker who decides greenness level $e^{\mathrm{MT}}$, recycling rate $\tau^{\mathrm{MT}}$, and wholesale price $w^{\mathrm{MT}}$. Subsequently, $R$ decides service level $s^{\mathrm{MT}}$ and retailer price $p^{\mathrm{MT}}$. In this case, alliance MT and $R$ play a Stackelberg game. The alliance model is formulated as

$$
\begin{aligned}
& \max _{e^{\mathrm{MT}}, \tau^{\mathrm{MT}}, w^{\mathrm{MT}}} \prod_{m t}^{\mathrm{MT}}=\left(w^{\mathrm{MT}}-c_{n}+\Delta \tau^{\mathrm{MT}}\right)\left(Q-\alpha p^{\mathrm{MT}}+\beta e^{\mathrm{MT}}+\gamma s^{\mathrm{MT}}\right) \\
& -\frac{1}{2} c_{g} e^{\mathrm{MT} 2}-c_{R} \tau^{\mathrm{MT} 2} \\
& \text { s.t. } \max _{s^{\mathrm{MT}}, p^{\mathrm{MT}}} \prod_{r}^{\mathrm{MT}}=\left(p^{\mathrm{MT}}-w^{\mathrm{MT}}\right)\left(\mathrm{Q}-\alpha p^{\mathrm{MT}}+\beta e^{\mathrm{MT}}+\gamma s^{\mathrm{MT}}\right) \\
& -\frac{1}{2} c_{s} s^{\mathrm{MT} 2} .
\end{aligned}
$$

By using the reverse induction, we obtain the optimal results for the model MT, which are described in Proposition 3.

Proposition 3. In the model $M T$, the optimal results are given as $e^{M T *}=2 \beta c_{R} c_{s} \phi_{1} /\left(2 c_{R} \phi_{2}-c_{g} c_{s} \alpha^{2} \Delta^{2}\right), \quad s^{M T *}=2 \gamma$ $c_{R} c_{g} \phi_{1} /\left(2 c_{R} \phi_{2}-c_{g} c_{s} \alpha^{2} \Delta^{2}\right), \quad w^{M T *}=c_{n}+c_{g}\left(4 c_{R} c_{s} \alpha-c_{s} \alpha^{2}\right.$ $\left.\Delta^{2}-2 c_{R} \gamma^{2}\right) \phi_{1} /\left(\alpha\left(2 c_{R} \phi_{2}-c_{g} c_{s} \alpha^{2} \Delta^{2}\right)\right), p^{M T *}=c_{n}+c_{g}\left(6 c_{R} c_{s}\right.$ $\left.\alpha-c_{s} \alpha^{2} \Delta^{2}-2 c_{R} \gamma^{2}\right) \phi_{1} /\left(\alpha\left(2 c_{R} \phi_{2}-c_{g} c_{s} \alpha^{2} \Delta^{2}\right)\right)$, and $\tau^{M T *}=$ $\alpha c_{g} c_{s} \Delta \phi_{1} /\left(2 c_{R} \phi_{2}-c_{g} c_{s} \alpha^{2} \Delta^{2}\right)$.

The proof is given in Appendix $C$.

And thus, the optimal demand and profit are shown as $D^{M T *}=2 \alpha c_{R} c_{g} c_{s} \phi_{1} /\left(2 c_{R} \phi_{2}-c_{g} c_{s} \alpha^{2} \Delta^{2}\right), \quad \prod_{m t}^{M T *}=c_{R} c_{g} c_{s} \phi_{1}^{2} /$ $\left(2 c_{R} \phi_{2}-c_{g} c_{s} \alpha^{2} \Delta^{2}\right)$, and $\prod_{r}^{M T *}=2 c_{R}^{2} c_{g}^{2} c_{s}\left(2 \alpha c_{s}-\gamma^{2}\right) \phi_{1}^{2} /$ $\left(2 c_{R} \phi_{2}-c_{g} c_{s} \alpha^{2} \Delta^{2}\right)^{2}$.

The optimal consumer surplus, environmental improvement, and social welfare are shown as

$$
\begin{aligned}
\mathrm{CS}^{\mathrm{MT} *} & =\frac{2 \alpha c_{R}^{2} c_{g}^{2} c_{s}^{2} \phi_{1}^{2}}{\left(2 c_{R} \phi_{2}-c_{g} c_{s} \alpha^{2} \Delta^{2}\right)^{2}}, \\
\mathrm{EI}^{\mathrm{MT} *} & =\frac{4 c_{e} \beta c_{R}^{2} c_{s}^{2} \alpha c_{g} \phi_{1}^{2}}{\left(2 c_{R} \phi_{2}-c_{g} c_{s} \alpha^{2} \Delta^{2}\right)^{2}}, \\
\mathrm{SW}^{\mathrm{MT} *} & =\prod_{m t}^{\mathrm{MT} *}+\prod_{r}^{\mathrm{MT} *}+\mathrm{CS}^{\mathrm{MT} *}+\mathrm{EI}^{\mathrm{MT} *} .
\end{aligned}
$$


4.4. $M, R$, and T Form an Alliance (Model $C$ ). In the model $C$, $M, R$, and $T$ form an alliance, in which a centralized planner makes decisions of greenness $e^{C}$, service level $s^{C}$, recycling rate $\tau^{C}$, and retail price $p^{C}$ for all CLSC members to maximize the CLSC profit. The optimization problem is formulated as

$$
\max _{e^{C}, s^{C}, \tau^{C}, p^{C}} \prod_{c}^{C}=\left(p^{C}-c_{n}+\Delta \tau^{C}\right)\left(Q-\alpha p^{C}+\beta e^{C}+\gamma s^{C}\right)-\frac{1}{2} c_{g} e^{C 2}-\frac{1}{2} c_{s} s^{C 2}-c_{R} \tau^{C 2} .
$$

By using the reverse induction, we obtain the optimal results for the model $C$, which are described in Proposition 4.

Proposition 4. In the model $C$, the optimal results are given as $e^{C *}=2 \beta c_{R} c_{s} \phi_{1} /\left(2 c_{R} \phi_{3}-c_{g} c_{s} \alpha^{2} \Delta^{2}\right) \quad s^{C *}=2 c_{g} \gamma c_{R} \phi_{1} /$ $\left(2 c_{R} \phi_{3}-c_{g} c_{s} \alpha^{2} \Delta^{2}\right), p^{C *}=c_{n}+c_{g} c_{s}\left(2 c_{R}-\alpha \Delta^{2}\right) \phi_{1} /\left(2 c_{R} \phi_{3}-\right.$ $\left.c_{g} c_{s} \alpha^{2} \Delta^{2}\right)$, and $\tau^{C *}=\Delta \alpha c_{g} c_{s} \phi_{1} /\left(2 c_{R} \phi_{3}-c_{g} c_{s} \alpha^{2} \Delta^{2}\right)$.

The proof is given in Appendix $D$.

And thus, the optimal demand and profit are shown as $D^{C *}=2 \alpha c_{R} c_{g} c_{s} \phi_{1} /\left(2 c_{R} \phi_{3}-c_{g} c_{s} \alpha^{2} \Delta^{2}\right)$ and $\prod_{c}^{C *}=c_{R} c_{g}$ $c_{s} \phi_{1}^{2} /\left(2 c_{R} \phi_{3}-c_{g} c_{s} \alpha^{2} \Delta^{2}\right)$.

The optimal consumer surplus, environmental improvement, and social welfare are shown as

$$
\begin{aligned}
\mathrm{CS}^{C *} & =\frac{2 \alpha c_{R}^{2} c_{g}^{2} c_{s}^{2} \phi_{1}^{2}}{\left(2 c_{R} \phi_{3}-c_{g} c_{s} \alpha^{2} \Delta^{2}\right)^{2}}, \\
\mathrm{EI}^{C *} & =\frac{4 c_{e} \beta c_{R}^{2} c_{s}^{2} \alpha c_{g} \phi_{1}^{2}}{\left(2 c_{R} \phi_{3}-c_{g} c_{s} \alpha^{2} \Delta^{2}\right)^{2}}, \\
\mathrm{SW}^{C *} & =\prod_{c}^{C *}+\mathrm{CS}^{C *}+\mathrm{EI}^{C *} .
\end{aligned}
$$

4.5. Comparative Analysis of Equilibrium Results. Comparing the optimal results in the above four models, we obtain the following propositions.

Proposition 5. The retail price and transfer price in the four models satisfy

(1) $p^{C *}<p^{M R *}<p^{M T *}<p^{D *}$

(2) $b^{D *}=b^{M R *}$

The proof is given in Appendix E.

Proposition 5 shows that the retail price in the model $C$ is the lowest, while the retail price in the model $D$ is the highest. The retail price in the model MR is lower than that in the model MT. The different double marginalization scenarios lead to distinct retail prices. This is because supply chain member cooperation eliminates the impact of double marginalization. Since $R$ is closer to the target market, the MR alliance can reduce the retail price more significantly. Moreover, the transfer price paid by $M$ to $T$ in the model $D$ is the same as that in the model MR. That is to say, the MR alliance strategy does not affect the transfer price. This is because the alliance strategy of $M$ and $R$ pays more attention to the retail market. In order to promote the recycling of $T$, the MR alliance strategy will maintain the transfer price paid to $T$ at a stable level.

Proposition 6. The greenness level, service level, and recycling rate satisfy

(1) $e^{D *}<e^{M T *}<e^{M R *}<e^{C *}$

(2) $s^{D *}<s^{M T *}<s^{M R *}<s^{C *}$

(3) $\tau^{D *}<\tau^{M T *}<\tau^{M R *}<\tau^{C *}$

The proof is given in Appendix F.

Proposition 6 shows that the greenness level, service level, and recycling rate are all the highest in the model $C$, while they are all the lowest in the model $D$. The greenness level, service level, and recycling rate in the model MR are higher than those in the model MT. The different double marginalization scenarios lead to distinct greenness levels, service levels, and recycling rates. Under a decentralized scenario, $M$ offers the lowest greenness level, $R$ offers the lowest service level, and $T^{\prime}$ recycling rate is the lowest. Comparing MT alliance strategy, MR alliance strategy can encourage $M, R$, and $T$ to improve the greenness level, service level, and recycling rate, respectively.

Proposition 7. The demand satisfies $D^{D *}<D^{M T *}<$ $D^{M R *}<D^{C *}$.

The proof is given in Appendix G.

Proposition 7 shows that the market demand in the model $D$ is the lowest, while it is the highest in the model $C$. The demand in the model MR is higher than that in the model MT. That is because, in the model $C, R$ sets the lowest retail price and offers the highest service level, and $M$ offers the highest greenness level. Comparing the case under MT alliance strategy, MR alliance strategy can increase the consumer demand.

Proposition 8. The profit of supply chain member satisfies

(1) $\prod_{t}^{D *}<\prod_{t}^{M R *}$ and $\prod_{r}^{D *}<\prod_{r}^{M T *}$

(2) $\prod_{m}^{D *}+\prod_{r}^{D *}<\prod_{m r}^{M R *}$ and $\prod_{m}^{D *}+\prod_{t}^{D *}<\prod_{m t}^{M T *}$

(3) $\prod_{m t}^{M T *}<\prod_{m r}^{M R *}$

(4) $\prod_{c}^{D *}<\prod_{c}^{M T *}<\prod_{c}^{M R *}<\prod_{c}^{C *}$

The proof is given in Appendix $H$.

Proposition 8 shows that comparing the decentralized scenario, $T$ can obtain higher profit under the MR alliance 
strategy. Similarly, comparing the decentralized scenario, $R$ can obtain higher profit under the MT alliance strategy. That is to say, MR or MT alliance strategy has a benefit for $T$ or $R$. In addition, comparing the case of $M$ and $R$ that make their profit maximization decisions, respectively, MR alliance strategy can increase the total profit of $M$ and $R$. Similarly, comparing the case of $M$ and $T$ that make their profit maximization decision, respectively, $\mathrm{MT}$ alliance strategy can increase the total profit of $M$ and $T$. The MR and MT alliance strategies have a benefit for their members. Moreover, the total profit of $M$ and $T$ under the MT alliance strategy is lower than that of $M$ and $R$ under the MR alliance strategy; i.e., the MR alliance strategy has more benefit for its members than the MT alliance strategy. The CLSC profit in the model $C$ is the highest, while the CLSC profit in the model $D$ is the lowest. Moreover, the CLSC profit under the MR alliance strategy is higher than that under the MT alliance strategy. The double marginalization will damage the efficiency of the CLSC in varying degrees. Alliance strategy can alleviate this double marginalization.

Proposition 9. The consumer surplus, environmental improvement, and social welfare satisfy

(1) $C S^{D *}<C S^{M T *}<C S^{M R *}<C S^{C *}$

(2) $E I^{D *}<E I^{M T *}<E I^{M R *}<E I^{C *}$

(3) $S W^{D *}<S W^{M T *}<S W^{M R *}<S W^{C *}$

The proof is given in Appendix I.

Proposition 9 shows that the consumer surplus, environment improvement, and social welfare are the lowest under the decentralized scenario, while they the highest under the centralized scenario. The consumer surplus, environmental improvement, and social welfare in the model MR are higher than those in the model MT, respectively. The centralized scenario has the most benefit for consumers, the environment, and society. Comparing the case under MT alliance strategy, MR alliance strategy has more benefit for consumers, environment, and society; i.e., alliance strategy can improve the consumer surplus, environmental damage, and social welfare.

\section{Numerical Analysis}

To illustrate the impact of alliance strategies on the performance of the CLSC, consumer surplus, environmental improvement, and social welfare, a numerical experimental is given in this section. According to the previous assumptions and parameter ranges, the parameters are setting as $Q=20, b=4, c_{n}=2, c_{r}=1, \Delta=c_{n}-c_{r}=1, \gamma=1, \alpha=5$, $\beta=2, c_{g}=2, c_{s}=1$, and $c_{e}=2$. According to the assumption $\quad c_{R}>\max \left\{\left(\alpha \Delta^{2} / 2\right), \quad\left(\alpha c_{g} c_{s} \Delta\left(Q-\alpha c_{n}+\alpha \Delta\right) / 2\right.\right.$ $\left.\left.\left(2 \alpha c_{g} c_{s}-c_{s} \beta^{2}-c_{g} \gamma^{2}\right)\right)\right\}, \quad c_{R}$ varied within the range of $[5,10]$. Firstly, the effect of alliance strategy on the CLSC members' profits is shown in Figure 2.

Figure 2 shows that, with the increase of recycling cost coefficient $c_{R}$, the profits of CLSC members, alliance, and supply chain all decrease. The increase in recycling costs is disadvantageous to the CLSC operation. T should adopt new technologies to reduce recycling costs. Moreover, comparing the case under the decentralized scenario, alliance strategy can effectively improve the profits of CLSC members and total CLSC. MR alliance strategy can bring a higher profit for its members than the MT alliance strategy. Under some conditions, the MR alliance strategy can also increase the CLSC's profit. However, alliance strategy cannot make the profit reach the level of the centralized scenario. It needs to design a coordination contract to make all supply chain members cooperate to improve the CLSC's profit and heighten the operational efficiency of CLSC.

The impact of alliance strategy on consumer surplus, environmental improvement, and social welfare is illustrated in Figure 3.

From Figure 3, we can find that, with the increase of recycling cost coefficient $c_{R}$, the consumer surplus, environmental improvement, and social welfare all decrease. The increase in recycling costs is disadvantageous to consumers, the environment, and society. Under the centralized scenario, the consumer surplus, environment improvement, and social welfare are all the highest. But under the decentralized scenario, they are the lowest. Comparing the case under the decentralized scenario, the alliance strategy can increase consumer surplus, environment improvement, and social welfare while they cannot reach the level of the centralized scenario. From the angle of the consumer, environment, and society, the MR alliance strategy is more effective than the MT alliance strategy.

\section{Managerial Insights}

With the increase of environmental pollution, environmental problems have been widely concerned by the government, enterprises, and consumers. Consumers' purchasing behavior changes because of green preference. In order to meet the green preference of consumers and undertake the corporate social responsibility of environmental improvement, many manufacturing enterprises begin to invest in the R\&D of green products. Retail enterprises try to guide consumer green behavior by providing sales services. Recycling enterprises also invest cost to actively carry out recycling used products. Facing huge investment costs, alliance strategy is a solution to address green $\mathrm{R} \& \mathrm{D}$ and service effort. This article helps to develop a broader perspective regarding profit maximization in a CLSC.

Since $R$ has no direct contact with $T$, it will not form an alliance. Three alliance strategies are analyzed in this paper, and a decentralized scenario is used as a benchmark model. Comparing the decentralized scenario, alliance strategy can promote demand, product $\mathrm{R} \& \mathrm{D}$ and recycling, and service effort and improve CLSC's profit, consumer surplus, environmental quality, and social welfare. The $\mathrm{C}$ alliance strategy is always advantageous to the CLSC, consumer, environment, and society. The MR alliance strategy is more effective than the MT alliance strategy.

Alliance strategy in CLSC is an implementation issue that needs to address carefully. The effect of CLSC members to form alliances needs to be identified. Implementation of alliance decisions is essential for competitive as well as advantages. The proposed model explores that the 


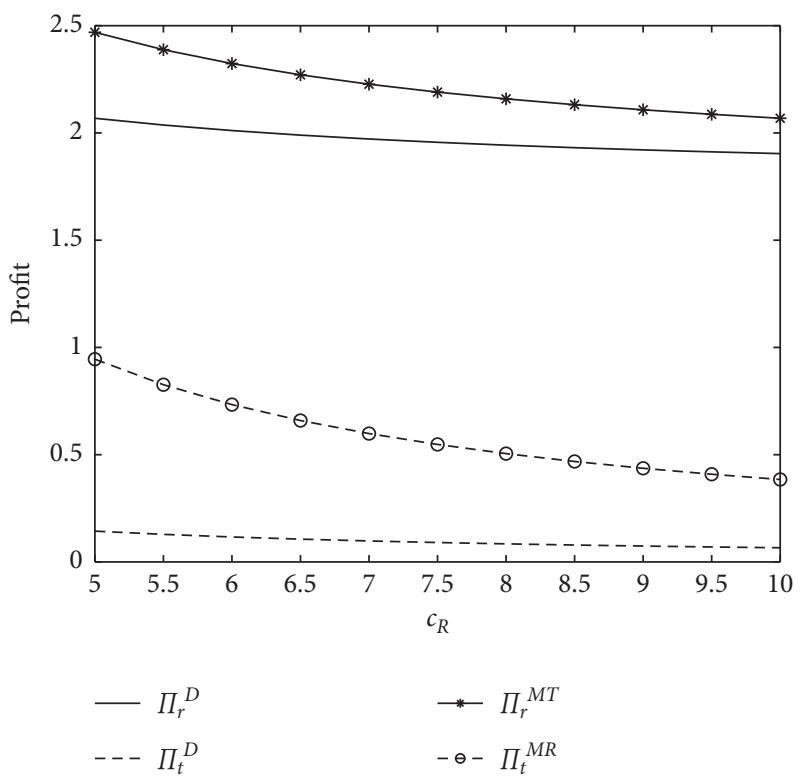

(a)

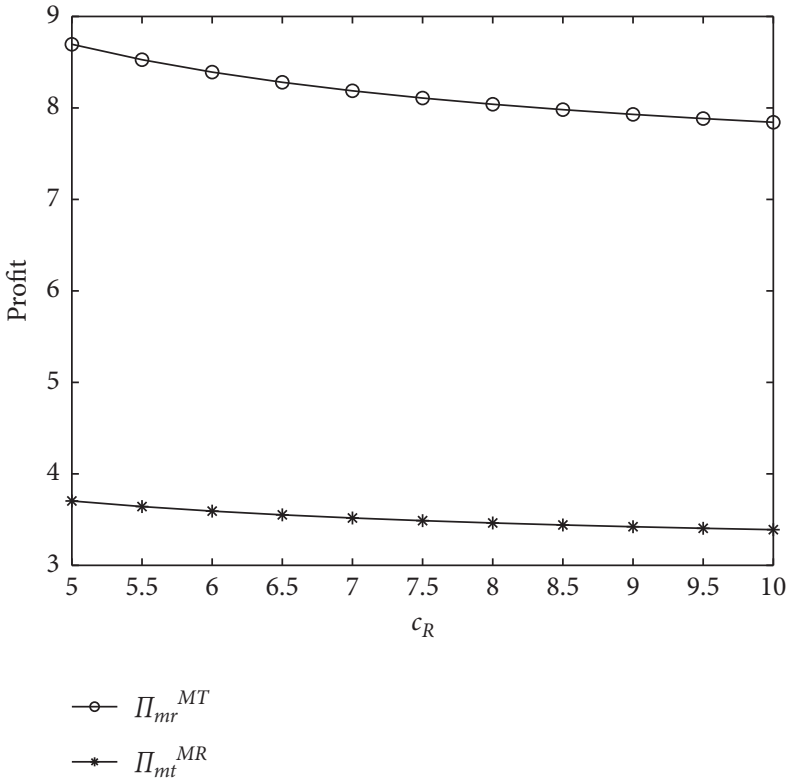

(b)

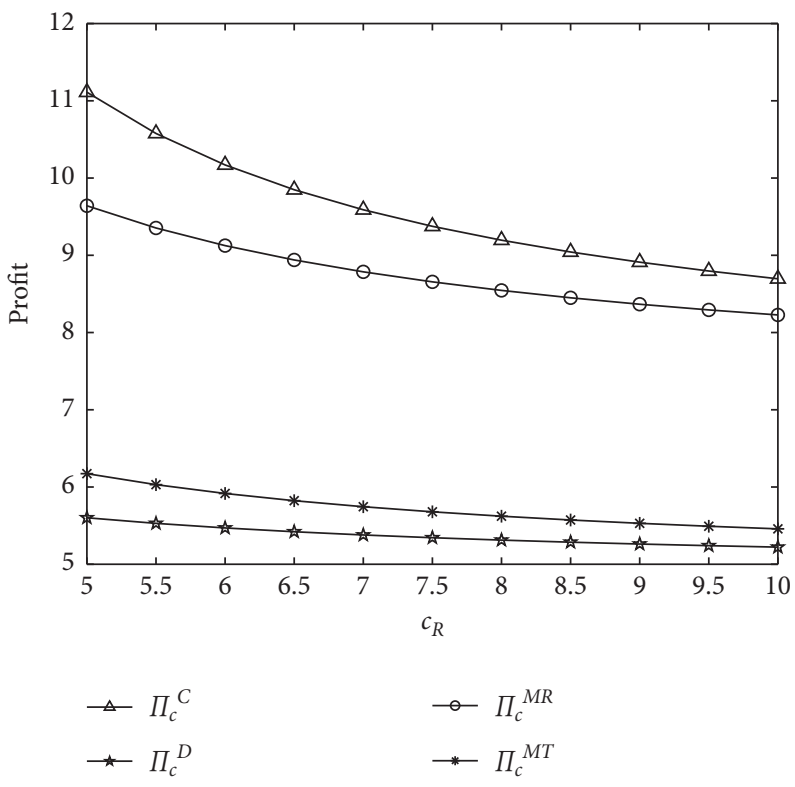

(c)

FIgURE 2: The impact of alliance strategy on CLSC members' profits.

decentralized scenario has no ability to improve the CLSC's operational efficiency. The $M, R$, and $T$ alliance is the best strategy for CLSC, consumer, environment, and society, but the centralized alliance strategy is an ideal state and difficult to implement. Comparing the MT alliance strategy, the MR alliance strategy has the ability to improve the performance of CLSC, consumers, the environment, and society. 


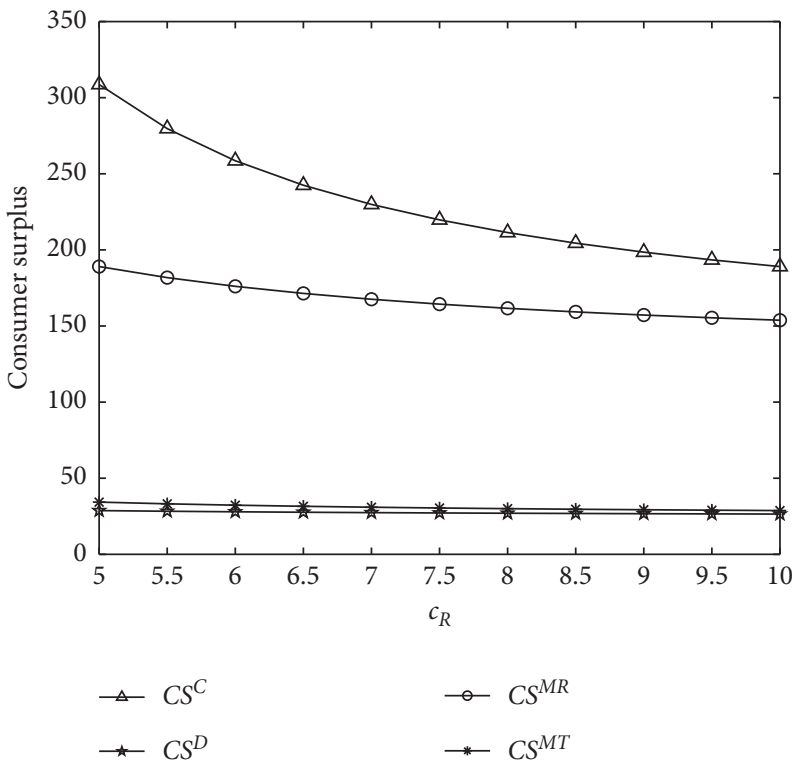

(a)

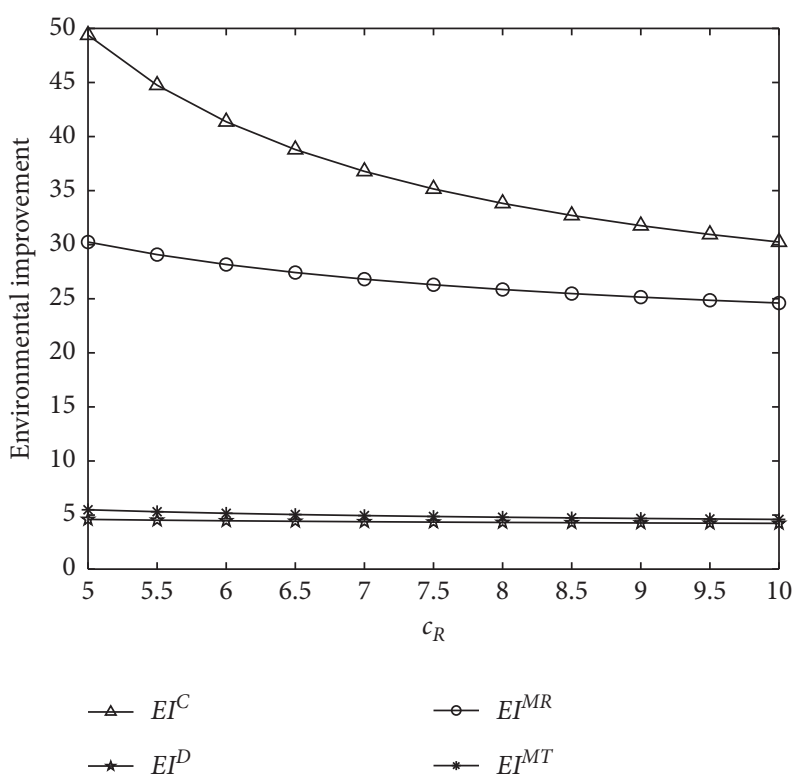

(b)

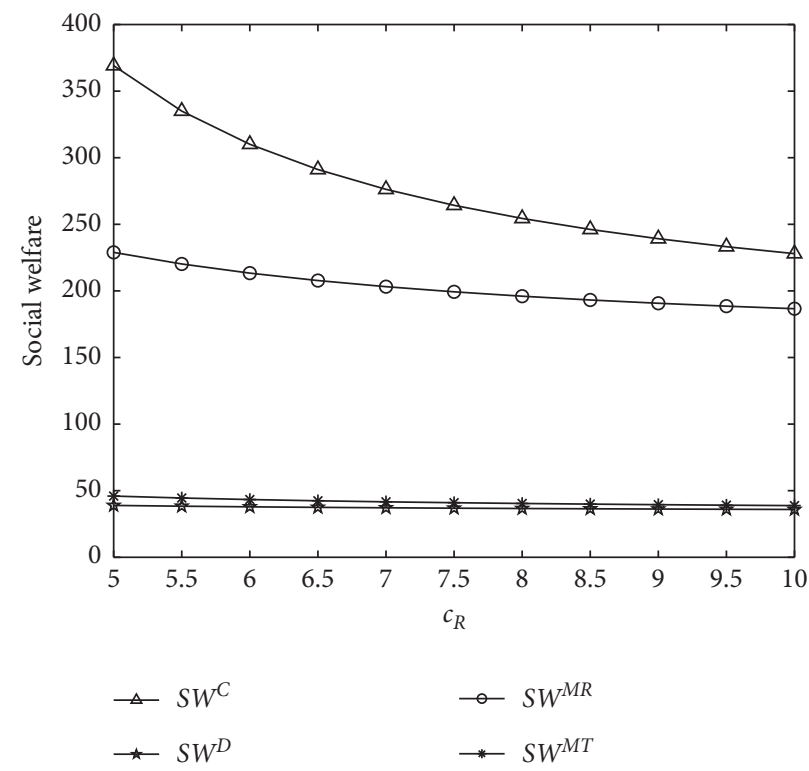

(c)

FIgURE 3: The impact of alliance strategy on the consumer, environment, and society.

\section{Conclusions}

Based on a CLSC consisting of $M, R$, and $T$, this paper takes $M$ and $R$ forming an alliance, $M$ and $T$ forming an alliance, and $M, R$, and $T$ forming a centralized alliance into account by considering the greenness and service effort. In the CLSC, $M$ produces and remanufactures products and wholesales the new and remanufactured products to $R$. $R$ sells the new and remanufactured products to consumers. And T recycles the used products from consumers and transfers them to $M$. Considering different alliance strategies, four models $D$, $M R, M T$, and $C$ are constructed. Moreover, the effect of alliance strategy on consumers, the environment, and society is also analyzed. The results show that (1) under alliance strategy scenario, the greenness level, service level, and recycling rate are higher than those under decentralized scenario (no alliance), and (2) C centralized alliance strategy generates the most CLSC's profit, consumer surplus, environmental improvement, and social welfare. The MR alliance strategy is more effective than the MT alliance strategy. $M$ always prefers MR alliance strategy.

The above results show that the consumers are to be attracted toward green product if the retail price is fair, and product marketing and service effort are well implemented. Although enterprises need to undertake the corporate social responsibility of environmental protection, many enterprises are not being interested to produce and develop green products and provide service effort because of high 
investment. This proposed model helps the management of an enterprise to attract consumers to purchase more green products by implementing proper pricing and alliance strategies. The findings from the results assure us that the enterprise manager forms an alliance to give attention to the green product development and service effort, which is a benefit for CLSC, consumers, the environment, and society.

To capture the market for green products and using alliance strategy, there are limitations of three societal actors: enterprises, consumers, and government. Firstly, enterprises need to balance the costs and benefits of green product development and the benefit brought by alliance strategy. Its objective is to maximize its own profits rather than social welfare. Secondly, the purchase behavior of consumers depends on the prices, services, and other factors. Consumers also pay less attention to environmental issues and less attention to the alliance strategy between CLSC members. Only when green products can bring them more benefits, they will choose to buy green products. Finally, the government pays more attention to environmental issues, but it does not pay attention to enterprise alliance strategy. The government can only restrict the behavior of enterprises by making policies, and the restriction on consumer green behavior is negligible.

However, government regulation is not a remedy for green marketing and green products $\mathrm{R} \& \mathrm{D}$. It is important to appreciate that CLSC members forming alliances to develop green products and provide services can be achievable, and it can reduce the harm to the environment and society. Recently, many enterprises form alliances to carry out green products $\mathrm{R} \& \mathrm{D}$ and used products recycling as long as the design of cooperation mechanism is reasonable. The implementation of the CLSC member alliance strategy not only stimulates consumer demand but also solves environmental and social issues. Generally speaking, environmental issues can be solved by the market. As long as the strategy can bring benefits to the enterprise, they will take the initiative to implement it.

There are still some problems not considered in this paper. Firstly, this article only considers the CLSC consisting of one traditional retail channel. In reality, with the development of the online channel, different recycling channel modes and alliance strategies in dual-channel CLSC will be investigated in future research. Secondly, this paper assumed the new and remanufactured products are homogeneous and consumers have the same preference for the two kinds of products while some kinds of new and remanufactured products are heterogeneous, and consumers have different preferences for new and remanufactured products. It is worthwhile to incorporate heterogeneous products and market segmentation of consumers into the CLSC. Finally, this paper only considers the third-party recycler responsible for recycling used products. In practice, there exist many recycling modes, such as retailer recycling, manufacturer recycling, or forming alliances for recycling. Different recycling modes will be considered to extend the proposed model in future research.

\section{Appendix}

\section{A. Proof of Proposition 1}

In the model $D$, the Hessian matrix of $\prod_{r}^{D}$ in terms of $p^{D}$ and $s^{D} \quad$ is $\quad H^{D 1}=\left[\begin{array}{cc}-2 \alpha & \gamma \\ \gamma & -c_{s}\end{array}\right]$. From the assumption $\alpha c_{g} c_{s}>c_{s} \beta^{2}+c_{g} \gamma^{2}$, it can be shown that $\left|H_{1}^{D 1}\right|=-2 \alpha<0,\left|H_{2}^{D 1}\right|=2 \alpha c_{s}-\gamma^{2}>0$. Therefore, $H^{D 1}$ is negative definite, and $\prod_{r}^{D}$ is strictly concave with respect to $p^{D}$ and $s^{D}$. Since $\left(\partial^{2} \prod_{t}^{D} / \partial \tau^{D 2}\right)=-2 c_{R}<0, \prod_{t}^{D}$ is concave on $\tau^{D}$. It can be obtained from $\left(\partial \prod_{r}^{D} / \partial p^{D}\right)=0$, $\left(\partial \prod_{r}^{D} / \partial s^{D}\right)=0$, and $\left(\partial \prod_{t}^{D} / \partial \tau^{D}\right)=0$ that $p^{D}=$ $\left(\left(\alpha c_{s}-\gamma^{2}\right) w+c_{s}(Q+\beta e)\right) /\left(2 \alpha c_{s}-\gamma^{2}\right), \quad s^{D}=\gamma(Q+\beta e-$ $\alpha w) /\left(2 \alpha c_{s}-\gamma^{2}\right), \quad$ and $\quad \tau^{D}=\alpha b c_{s}(Q+\beta e-\alpha w) /$ $\left(2 c_{R}\left(2 \alpha c_{s}-\gamma^{2}\right)\right)$.

By substituting $p^{D}, s^{D}$, and $\tau^{D}$ into $\prod_{m}^{D}$, the Hessian matrix of $\prod_{m}^{D}$ in terms of $w^{D}, b^{D}$, and $e^{D}$ is

$$
H^{D 2}=\left[\begin{array}{cc}
\frac{-\alpha^{2} c_{s}\left[c_{s} \alpha^{2} b(b-\Delta)+2 c_{R}\left(2 c_{s} \alpha-\gamma^{2}\right)\right]}{c_{R}\left(2 \alpha c_{s}-\gamma^{2}\right)^{2}} & \frac{\alpha \beta c_{s}\left[c_{s} \alpha^{2} b(b-\Delta)+c_{R}\left(2 c_{s} \alpha-\gamma^{2}\right)\right]}{c_{R}\left(2 \alpha c_{s}-\gamma^{2}\right)^{2}} \\
\frac{\alpha \beta c_{s}\left[c_{s} \alpha^{2} b(b-\Delta)+c_{R}\left(2 c_{s} \alpha-\gamma^{2}\right)\right]}{c_{R}\left(2 \alpha c_{s}-\gamma^{2}\right)^{2}} & \frac{\alpha^{2} b \beta^{2} c_{s}^{2}(\Delta-b)-c_{R} c_{g}\left(2 \alpha c_{s}-\gamma^{2}\right)^{2}}{c_{R}\left(2 \alpha c_{s}-\gamma^{2}\right)^{2}}
\end{array}\right] .
$$


From the assumptions $c_{R}>\left(\alpha c_{g} c_{s} \Delta\left(Q-\alpha c_{n}+\alpha \Delta\right) /\right.$ $\left.\left(2\left(2 \alpha c_{g} c_{s}-c_{s} \beta^{2}-c_{g} \gamma^{2}\right)\right)\right)$ and $\Delta>b>0$, it can be shown that

$$
\begin{aligned}
& \left|H_{1}^{D 2}\right|=\frac{-\alpha^{2} c_{s}\left[c_{s} \alpha^{2} b(b-\Delta)+2 c_{R}\left(2 c_{s} \alpha-\gamma^{2}\right)\right]}{c_{R}\left(2 \alpha c_{s}-\gamma^{2}\right)^{2}}<0, \\
& \left|H_{2}^{D 2}\right|=\frac{\alpha^{2} c_{s}\left[\alpha^{2} b c_{g} c_{s}(b-\Delta)+c_{R} \phi_{2}\right]}{c_{R}\left(2 \alpha c_{s}-\gamma^{2}\right)^{2}}>0 .
\end{aligned}
$$

Therefore, $H^{D 2}$ is negative definite, and $\prod_{m}^{D}$ is strictly concave with respect to $w^{D}$ and $e^{D}$. It can be obtained from $\left(\partial \prod_{m}^{D} / \partial w^{D}\right)=0$ and $\left(\partial \prod_{m}^{D} / \partial e^{D}\right)=0$ that

$$
\begin{aligned}
w^{D} & =\frac{Q c_{g}\left[c_{s} \alpha^{2} b(b-\Delta)+c_{R}\left(2 c_{s} \alpha-\gamma^{2}\right)\right]+c_{R} c_{n} \alpha \phi_{3}}{\alpha\left[c_{g} c_{s} \alpha^{2} b(b-\Delta)+c_{R} \phi_{2}\right]}, \\
e^{D} & =\frac{c_{R} \beta c_{s} \phi_{1}}{c_{g} c_{s} \alpha^{2} b(b-\Delta)+c_{R} \phi_{2}} .
\end{aligned}
$$

Substituting $w^{D}$ and $e^{D}$ into $\prod_{m}^{D}$, we have $b^{D *}=(\Delta / 2)$. Substituting $b^{D *}=(\Delta / 2)$ into $w^{D}, e^{D}, p^{D}, s^{D}$, and $\tau^{D}$, we have

$$
\begin{aligned}
e^{D *} & =\frac{4 \beta c_{s} c_{R} \phi_{1}}{4 c_{R} \phi_{2}-\alpha^{2} c_{g} c_{s} \Delta^{2}}, \\
s^{D *} & =\frac{4 \gamma c_{R} c_{g} \phi_{1}}{4 c_{R} \phi_{2}-\alpha^{2} c_{g} c_{s} \Delta^{2}}, \\
w^{D *} & =c_{n}+\frac{c_{g}\left(8 c_{R} c_{s} \alpha-c_{s} \alpha^{2} \Delta^{2}-4 c_{R} \gamma^{2}\right) \phi_{1}}{\alpha\left(4 c_{R} \phi_{2}-\alpha^{2} c_{g} c_{s} \Delta^{2}\right)}, \\
p^{D *} & =c_{n}+\frac{c_{g}\left(12 c_{R} c_{s} \alpha-c_{s} \alpha^{2} \Delta^{2}-4 c_{R} \gamma^{2}\right) \phi_{1}}{\alpha\left(4 c_{R} \phi_{2}-\alpha^{2} c_{g} c_{s} \Delta^{2}\right)}, \\
\tau^{D *} & =\frac{\alpha c_{g} c_{s} \Delta \phi_{1}}{4 c_{R} \phi_{2}-\alpha^{2} c_{g} c_{s} \Delta^{2}} .
\end{aligned}
$$

\section{B. Proof of Proposition 2}

In the model $\mathrm{MR}$, since $\left(\partial^{2} \prod_{t}^{\mathrm{MR}} / \partial \sigma^{\mathrm{MR} 2}\right)=-2 c_{R}<0, \Pi_{t}^{\mathrm{MR}}$ is concave on $\tau^{\mathrm{MR}}$. It can be obtained from $\left(\partial \prod_{t}^{\mathrm{MR}} / \partial \tau^{\mathrm{MR}}\right)=0$ that $\tau^{\mathrm{MR}}=\left(b\left(Q+\beta e-\alpha p+\gamma_{s}\right) / 2 c_{R}\right)$. Substituting $\tau^{\mathrm{MR}}$ into $\prod_{m r}^{\mathrm{MR}}$, we have

$$
H^{\mathrm{MR} 1}=\left[\begin{array}{ccc}
\frac{-\alpha\left(\alpha b^{2}-\alpha \Delta b+2 c_{R}\right)}{c_{R}} & \frac{\gamma\left(\alpha b^{2}-\alpha \Delta b+c_{R}\right)}{c_{R}} & \frac{\beta\left(\alpha b^{2}-\alpha \Delta b+c_{R}\right)}{c_{R}} \\
\frac{\gamma\left(\alpha b^{2}-\alpha \Delta b+c_{R}\right)}{c_{R}} & \frac{-\left(b^{2} \gamma^{2}-\Delta b \gamma^{2}+c_{R} c_{s}\right)}{c_{R}} & \frac{-b \beta \gamma(b-\Delta)}{c_{R}} \\
\frac{\beta\left(\alpha b^{2}-\alpha \Delta b+c_{R}\right)}{c_{R}} & \frac{-b \beta \gamma(b-\Delta)}{c_{R}} & \frac{-\left(b^{2} \beta^{2}-\Delta b \beta^{2}+c_{R} c_{g}\right)}{c_{R}}
\end{array}\right] .
$$

From the assumptions $c_{R}>\left(\alpha c_{g} c_{s} \Delta\left(Q-\alpha c_{n}+\alpha \Delta\right) /\right.$ $\left.\left(2\left(2 \alpha c_{g} c_{s}-c_{s} \beta^{2}-c_{g} \gamma^{2}\right)\right)\right)$ and $\Delta>b>0$, it can be shown that

$$
\begin{aligned}
& \left|H_{1}^{\mathrm{MR} 1}\right|=\frac{-\alpha\left(\alpha b^{2}-\alpha \Delta b+2 c_{R}\right)}{c_{R}}<0, \\
& \left|H_{2}^{\mathrm{MR} 1}\right|=\frac{c_{s} \alpha^{2} b(b-\Delta)+c_{R}\left(2 c_{s} \alpha-\gamma^{2}\right)}{c_{R}}>0, \\
& \left|H_{3}^{\mathrm{MR} 1}\right|=\frac{-\left(c_{g} c_{s} \alpha^{2} b(b-\Delta)+c_{R} \phi_{3}\right)}{c_{R}}<0 .
\end{aligned}
$$

Therefore, $H^{\mathrm{MR} 1}$ is negative definite, and $\prod_{m r}^{\mathrm{MR}}$ is strictly concave with respect to $p^{\mathrm{MR}}, s^{\mathrm{MR}}$, and $e^{\mathrm{MR}}$. It can be obtained from $\left(\partial \prod_{m r}^{\mathrm{MR}} / \partial p^{\mathrm{MR}}\right)=0, \quad\left(\partial \prod_{m r}^{\mathrm{MR}} / \partial s^{\mathrm{MR}}\right)=0$, and $\left(\partial \prod_{m r}^{\mathrm{MR}} / \partial e^{\mathrm{MR}}\right)=0$ that

$$
\begin{aligned}
p^{\mathrm{MR}} & =\frac{Q c_{g} c_{s}\left(\alpha b^{2}-\alpha \Delta b+c_{R}\right)+c_{R} c_{n}\left(\phi_{3}-\alpha c_{g} c_{s}\right)}{c_{g} c_{s} \alpha^{2} b(b-\Delta)+c_{R} \phi_{3}}, \\
s^{\mathrm{MR}} & =\frac{c_{R} \gamma c_{g}\left(Q-\alpha c_{n}\right)}{c_{g} c_{s} \alpha^{2} b(b-\Delta)+c_{R} \phi_{3}}, \\
e^{\mathrm{MR}} & =\frac{c_{R} \beta c_{s}\left(Q-\alpha c_{n}\right)}{c_{g} c_{s} \alpha^{2} b(b-\Delta)+c_{R} \phi_{3}} .
\end{aligned}
$$


Substituting $p^{\mathrm{MR}}, s^{\mathrm{MR}}$, and $e^{\mathrm{MR}}$ into $\prod_{m}^{D}$, we have $b^{\mathrm{MR} *}=(\Delta / 2)$. Substituting $b^{\mathrm{MR} *}=(\Delta / 2)$ into $p^{\mathrm{MR}}, s^{\mathrm{MR}}$, $e^{\mathrm{MR}}$, and $\tau^{\mathrm{MR}}$, we have

$$
\begin{aligned}
e^{\mathrm{MR} *} & =\frac{4 \beta c_{R} c_{s} \phi_{1}}{4 c_{R} \phi_{3}-\alpha^{2} c_{g} c_{s} \Delta^{2}}, \\
s^{\mathrm{MR} *} & =\frac{4 c_{R} c_{g} \gamma \phi_{1}}{4 c_{R} \phi_{3}-\alpha^{2} c_{g} c_{s} \Delta^{2}}, \\
p^{\mathrm{MR} *} & =c n+\frac{c_{g} c_{s}\left(4 c_{R}-\alpha \Delta^{2}\right)}{4 c_{R} \phi_{3}-\alpha^{2} c_{g} c_{s} \Delta^{2}}, \\
\tau^{\mathrm{MR} *} & =\frac{\Delta \alpha c_{g} c_{s} \phi_{1}}{4 c_{R} \phi_{3}-\alpha^{2} c_{g} c_{s} \Delta^{2}} .
\end{aligned}
$$

\section{Proof of Proposition 3}

In the model MT, the Hessian matrix of $\prod_{r}^{\mathrm{MT}}$ in terms of $p^{\mathrm{MT}}$ and $s^{\mathrm{MT}}$ is $H^{\mathrm{MT} 1}=\left[\begin{array}{cc}-2 \alpha & \gamma \\ \gamma & -c_{s}\end{array}\right]$. From the assumption $\alpha c_{g} c_{s}>c_{s} \beta^{2}+c_{g} \gamma^{2}$, it can be shown that $\left|H_{1}^{\mathrm{MT} 1}\right|=-2 \alpha<0$ and $\left|H_{2}^{\mathrm{MT1}}\right|=2 \alpha c_{s}-\gamma^{2}>0$. Therefore, $H^{\mathrm{MT} 1}$ is negative definite, and $\prod_{r}^{\mathrm{MT}}$ is strictly concave with respect to $p^{\mathrm{MT}}$ and $s^{\mathrm{MT}}$. It can be obtained from $\left(\partial \prod_{r}^{\mathrm{MT}} / \partial p^{\mathrm{MT}}\right)=0$ and $\left(\partial \prod_{r}^{\mathrm{MT}} / \partial s^{\mathrm{MT}}\right)=0$ that $p^{\mathrm{MT}}=\left(Q c_{s}+\beta c_{s} e+\alpha c_{s} w-w \gamma^{2}\right) /$ $\left(2 \alpha c_{s}-\gamma^{2}\right)$ and $s^{\mathrm{MT}}=\gamma(Q+\beta e-\alpha w) /\left(2 \alpha c_{s}-\gamma^{2}\right)$.

By substituting $p^{\mathrm{MT}}$ and $s^{\mathrm{MT}}$ into $\prod_{m t}^{\mathrm{MT}}$, the Hessian matrix of $\prod_{m t}^{\mathrm{MT}}$ in terms of $w^{\mathrm{MT}}, \tau^{\mathrm{MT}}$, and $e^{\mathrm{MT}}$ is

$$
H^{\mathrm{MT}^{2}}=\left[\begin{array}{ccc}
\frac{-2 \alpha^{2} c_{s}}{2 \alpha c_{s}-\gamma^{2}} & \frac{\Delta \alpha^{2} c_{s}}{\gamma^{2}-2 \alpha c_{s}} & \frac{\alpha \beta c_{s}}{2 \alpha c_{s}-\gamma^{2}} \\
\frac{\Delta \alpha^{2} c_{s}}{\gamma^{2}-2 \alpha c_{s}} & -2 c_{R} & \frac{\Delta \alpha \beta c_{s}}{2 \alpha c_{s}-\gamma^{2}} \\
\frac{\alpha \beta c_{s}}{2 \alpha c_{s}-\gamma^{2}} & \frac{\Delta \alpha \beta c_{s}}{2 \alpha c_{s}-\gamma^{2}} & -c_{g}
\end{array}\right] .
$$

It can be shown that $\left|H_{1}^{\mathrm{MT} 2}\right|>0,\left|H_{2}^{\mathrm{MT} 2}\right|>0$, and $\left|H_{3}^{\mathrm{MT} 2}\right|<0$. Therefore, $H^{\mathrm{MT} 2}$ is negative definite, and $\prod_{m t}^{\mathrm{MT}}$ is strictly concave with respect to $w^{\mathrm{MT}}, \tau^{\mathrm{MT}}$, and $e^{\mathrm{MT}}$. It can be obtained from $\left(\partial \prod_{m t}^{\mathrm{MT}} / \partial w^{\mathrm{MT}}\right)=0,\left(\partial \prod_{m t}^{\mathrm{MT}} / \partial \tau^{\mathrm{MT}}\right)=0$, and $\left(\partial \prod_{m t}^{\mathrm{MT}} / \partial e^{\mathrm{MT}}\right)=0$ that

$$
\begin{aligned}
w^{\mathrm{MT} *} & =c_{n}+\frac{c_{g}\left(4 c_{R} c_{s} \alpha-c_{s} \alpha^{2} \Delta^{2}-2 c_{R} \gamma^{2}\right) \phi_{1}}{\alpha\left(2 c_{R} \phi_{2}-c_{g} c_{s} \alpha^{2} \Delta^{2}\right)}, \\
\tau^{\mathrm{MT} *} & =\frac{\alpha c_{g} c_{s} \Delta \phi_{1}}{2 c_{R} \phi_{2}-c_{g} c_{s} \alpha^{2} \Delta^{2}}, \\
e^{\mathrm{MT} *} & =\frac{2 \beta c_{R} c_{s} \phi_{1}}{2 c_{R} \phi_{2}-c_{g} c_{s} \alpha^{2} \Delta^{2}} .
\end{aligned}
$$
have

Substituting $w^{\mathrm{MT} *}, \tau^{\mathrm{MT} *}$, and $e^{\mathrm{MT} *}$ into $p^{\mathrm{MT}}$ and $s^{\mathrm{MT}}$, we

$$
p^{\mathrm{MT} *} c_{n}+\frac{c_{g}\left(6 c_{R} c_{s} \alpha-c_{s} \alpha^{2} \Delta^{2}-2 c_{R} \gamma^{2}\right) \phi_{1}}{\alpha\left(2 c_{R} \phi_{2}-c_{g} c_{s} \alpha^{2} \Delta^{2}\right)},
$$

$$
s^{\mathrm{MT} *}=\frac{2 \gamma c_{R} c_{g} \phi_{1}}{2 c_{R} \phi_{2}-c_{g} c_{s} \alpha^{2} \Delta^{2}} \text {. }
$$

\section{Proof of Proposition 4}

In the model $C$, the Hessian matrix of $\prod_{c}^{C}$ in terms of $p^{C}, s^{C}, \tau^{C}$, and $e^{C}$ is $H^{C}=\left[\begin{array}{cccc}-2 \alpha & \gamma & -\alpha \Delta & \beta \\ \gamma & -c_{s} & \Delta \gamma & 0 \\ -\alpha \Delta & \Delta \gamma & -2 c_{R} & \beta \Delta \\ \beta & 0 & \beta \Delta & -c_{g}\end{array}\right]$. It can be shown that

$\prod_{c}^{C}$ is strictly concave with respect to $p^{C}, s^{C}, \tau^{C}$, and $e^{C}$. From $\left(\partial \prod_{c}^{C} / \partial p^{C}\right)=0, \quad\left(\partial \prod_{c}^{C} / \partial s^{C}\right)=0, \quad\left(\partial \prod_{c}^{C} / \partial \tau^{C}\right)=0, \quad$ and $\left(\partial \prod_{c}^{C} / \partial e^{C}\right)=0$, we have

$$
\begin{aligned}
p^{C *} & =c_{n}+\frac{c_{g} c_{s}\left(2 c_{R}-\alpha \Delta^{2}\right) \phi_{1}}{2 c_{R} \phi_{3}-c_{g} c_{s} \alpha^{2} \Delta^{2}}, \\
s^{C *} & =\frac{2 c_{g} \gamma c_{R} \phi_{1}}{2 c_{R} \phi_{3}-c_{g} c_{s} \alpha^{2} \Delta^{2}}, \\
\tau^{C *} & =\frac{\Delta \alpha c_{g} c_{s} \phi_{1}}{2 c_{R} \phi_{3}-c_{g} c_{s} \alpha^{2} \Delta^{2}}, \\
e^{C *} & =\frac{2 \beta c_{R} c_{s} \phi_{1}}{2 c_{R} \phi_{3}-c_{g} c_{s} \alpha^{2} \Delta^{2}} .
\end{aligned}
$$




\section{E. Proof of Proposition 5}

(1) Comparing the optimal retail prices in the four models, we have

$$
\begin{aligned}
p^{\mathrm{MR} *}-p^{C *} & =\frac{2 \alpha c_{R} c_{g} c_{s} \Delta^{2}\left(\alpha c_{g} c_{s}-c_{s} \beta^{2}-c_{g} \gamma^{2}\right) \phi_{1}}{\left(4 c_{R} \phi_{3}-\alpha^{2} c_{g} c_{s} \Delta^{2}\right)\left(2 c_{R} \phi_{3}-c_{g} c_{s} \alpha^{2} \Delta^{2}\right)}>0, \\
p^{\mathrm{MT} *}-p^{\mathrm{MR} *} & =\frac{2 c_{R} c_{g}\left(\alpha c_{g} c_{s}-c_{s} \beta^{2}-c_{g} \gamma^{2}\right)\left(8 c_{R} c_{s} \alpha-c_{s} \alpha^{2} \Delta^{2}-4 c_{R} \gamma^{2}\right) \phi_{1}}{\alpha\left(2 c_{R} \phi_{2}-c_{g} c_{s} \alpha^{2} \Delta^{2}\right)\left(4 c_{R} \phi_{3}-\alpha^{2} c_{g} c_{s} \Delta^{2}\right)}>0, \\
p^{D *}-p^{\mathrm{MT} *} & =\frac{2 \alpha c_{R} c_{g} c_{s} \Delta^{2}\left(\alpha c_{g} c_{s}-c_{s} \beta^{2}-c_{g} \gamma^{2}\right) \phi_{1}}{\left(4 c_{R} \phi_{2}-\alpha^{2} c_{g} c_{s} \Delta^{2}\right)\left(2 c_{R} \phi_{2}-c_{g} c_{s} \alpha^{2} \Delta^{2}\right)}>0,
\end{aligned}
$$

andthus $p^{C *}<p^{\mathrm{MR} *}<p^{\mathrm{MT} *}<p^{D *}$.

(2) Comparing the optimal transfer prices in the models $D$ and $\mathrm{MR}$, we have $b^{D *}=b^{\mathrm{MR} *}=(\Delta / 2)$.

\section{F. Proof of Proposition 6}

(1) Comparing the optimal green levels of products in the four models, we have

$$
e^{\mathrm{MT} *}-e^{D *}=\frac{2 \alpha^{2} \beta c_{R} c_{g} c_{s}^{2} \Delta^{2} \phi_{1}}{\left(2 c_{R} \phi_{2}-c_{g} c_{s} \alpha^{2} \Delta^{2}\right)\left(4 c_{R} \phi_{2}-\alpha^{2} c_{g} c_{s} \Delta^{2}-\right)}>0,
$$$$
e^{\mathrm{MR} *}-e^{\mathrm{MT} *}=\frac{2 \beta c_{R} c_{g} c_{s}\left(8 c_{R} c_{s} \alpha-c_{s} \alpha^{2} \Delta^{2}-4 c_{R} \gamma^{2}\right) \phi_{1}}{\left(4 c_{R} \phi_{3}-\alpha^{2} c_{g} c_{s} \Delta^{2}\right)\left(2 c_{R} \phi_{2}-c_{g} c_{s} \alpha^{2} \Delta^{2}\right)}>0,
$$$$
e^{\mathrm{C} *}-e^{\mathrm{MR} *}=\frac{2 \alpha^{2} \beta c_{R} c_{g} c_{s}^{2} \Delta^{2} \phi_{1}}{\left(2 c_{R} \phi_{3}-c_{g} c_{s} \alpha^{2} \Delta^{2}\right)\left(4 c_{R} \phi_{3}-c_{g} c_{s} \alpha^{2} \Delta^{2}\right)}>0,
$$

and thus $e^{D *}<e^{\mathrm{MT} *}<e^{\mathrm{MR} *}<e^{C *}$.

(2) Comparing the optimal service efforts in the four models, we have

$$
\begin{gathered}
s^{\mathrm{MT} *}-s^{D *}=\frac{2 \alpha^{2} c_{R} c_{g}^{2} c_{s} \Delta^{2} \gamma \phi_{1}}{\left(2 c_{R} \phi_{3}-c_{g} c_{s} \alpha^{2} \Delta^{2}\right)\left(4 c_{R} \phi_{3}-c_{g} c_{s} \alpha^{2} \Delta^{2}\right)}>0, \\
s^{\mathrm{MR} *}-s^{\mathrm{MT} *}=\frac{2 c_{R} c_{g}^{2} \gamma\left(8 c_{R} c_{s} \alpha-c_{s} \alpha^{2} \Delta^{2}-4 c_{R} \gamma^{2}\right) \phi_{1}}{\left(2 c_{R} \phi_{3}-c_{g} c_{s} \alpha^{2} \Delta^{2}\right)\left(4 c_{R} \phi_{3}-c_{g} c_{s} \alpha^{2} \Delta^{2}\right)}>0, \\
s^{C *}-s^{\mathrm{MR} *}=\frac{2 \alpha^{2} c_{R} c_{g}^{2} c_{s} \Delta^{2} \gamma \phi_{1}}{\left(2 c_{R} \phi_{3}-c_{g} c_{s} \alpha^{2} \Delta^{2}\right)\left(4 c_{R} \phi_{3}-c_{g} c_{s} \alpha^{2} \Delta^{2}\right)}>0,
\end{gathered}
$$

thus $s^{D *}<s^{\mathrm{MT} *}<s^{\mathrm{MR} *}<s^{C *}$.

(3) Comparing the optimal recycle rates in the four models, we have

$$
\begin{gathered}
\tau^{\mathrm{MT} *}-\tau^{D *}=\frac{2 \alpha c_{R} c_{g} c_{s} \Delta \phi_{1} \phi_{2}}{\left(2 c_{R} \phi_{2}-c_{g} c_{s} \alpha^{2} \Delta^{2}\right)\left(4 c_{R} \phi_{2}-c_{g} c_{s} \alpha^{2} \Delta^{2}\right)}>0, \\
\tau^{\mathrm{MR} *}-\tau^{\mathrm{MT} *}=\frac{2 \alpha \beta^{2} c_{R} c_{g} c_{s}^{2} \Delta \phi_{1}}{\left(2 c_{R} \phi_{2}-c_{g} c_{s} \alpha^{2} \Delta^{2}\right)\left(4 c_{R} \phi_{3}-c_{g} c_{s} \alpha^{2} \Delta^{2}\right)}>0, \\
\tau^{C *}-\tau^{\mathrm{MR} *}=\frac{2 \alpha c_{R} c_{g} c_{s} \Delta \phi_{1} \phi_{2}}{\left(2 c_{R} \phi_{2}-c_{g} c_{s} \alpha^{2} \Delta^{2}\right)\left(4 c_{R} \phi_{3}-c_{g} c_{s} \alpha^{2} \Delta^{2}\right)},
\end{gathered}
$$

and thus $\tau^{D *}<\tau^{\mathrm{MT} *}<\tau^{\mathrm{MR} *}<\tau^{\mathrm{C*}}$

\section{G. Proof of Proposition 7}

Comparing the optimal market demands in the four models, we have

$$
\begin{gathered}
D^{\mathrm{MT} *}-D^{D *}=\frac{2 \alpha^{3} c_{R} c_{q}^{2} c_{s}^{2} \Delta^{2} \phi_{1}}{\left(2 c_{R} \phi_{2}-c_{g} c_{s} \alpha^{2} \Delta^{2}\right)\left(4 c_{R} \phi_{2}-c_{g} c_{s} \alpha^{2} \Delta^{2}\right)}>0, \\
D^{\mathrm{MR} *}-D^{\mathrm{MT} *} \frac{2 \alpha c_{R} c_{g}^{2} c_{s}\left(8 c_{R} c_{s} \alpha-c_{s} \alpha^{2} \Delta^{2}-4 c_{R} \gamma^{2}\right) \phi_{1}}{\left(2 c_{R} \phi_{2}-c_{g} c_{s} \alpha^{2} \Delta^{2}\right)\left(4 c_{R} \phi_{3}-c_{g} c_{s} \alpha^{2} \Delta^{2}\right)}, \\
D^{C *}-D^{\mathrm{MR} *}
\end{gathered}
$$

and thus $D^{D *}<D^{\mathrm{MT} *}<D^{\mathrm{MR} *}<D^{C *}$ 


\section{H. Proof of Proposition 8}

Comparing the profits of CLSC members in the four models, we have

$$
\begin{gathered}
\prod_{t}^{\mathrm{MR} *}-\prod_{t}^{D *}=\frac{8 \alpha^{2} c_{R}^{2} c_{g}^{3} c_{s}^{2} \Delta^{2} \phi_{1}^{2}\left(2 \alpha c_{s}-\gamma^{2}\right)\left(12 c_{R} c_{g} c_{s} \alpha-c_{g} c_{s} \alpha^{2} \Delta^{2}-4 c_{R} c_{s} \beta^{2}-6 c_{R} c_{g} \gamma^{2}\right)}{\left(2 c_{R} \phi_{3}-c_{g} c_{s} \alpha^{2} \Delta^{2}\right)^{2}\left(4 c_{R} \phi_{2}-c_{g} c_{s} \alpha^{2} \Delta^{2}\right)^{2}}>0 \\
\prod_{r}^{\mathrm{MT} *}-\prod_{r}^{D *}=\frac{2 \alpha^{2} c_{R}^{2} c_{g}^{3} c_{s}^{2} \Delta^{2} \phi_{1}^{2}\left(2 \alpha c_{s}-\gamma^{2}\right)\left(32 c_{R} c_{g} c_{s} \alpha-3 c_{g} c_{s} \alpha^{2} \Delta^{2}-8 c_{R} c_{s} \beta^{2}-16 c_{R} c_{g} \gamma^{2}\right)}{\left(2 c_{R} \phi_{2}-c_{g} c_{s} \alpha^{2} \Delta^{2}\right)^{2}\left(4 c_{R} \phi_{2}-c_{g} c_{s} \alpha^{2} \Delta^{2}\right)^{2}}>0 \\
\prod_{m r}^{\mathrm{MR} *}-\prod_{m}^{D *}-\prod_{r}^{D *}=\frac{32 c_{R}^{3} c_{g}^{3} c_{s}\left(2 \alpha c_{s}-\gamma^{2}\right)^{2} \phi_{1}^{2}}{\left(4 c_{R} \phi_{2}-c_{g} c_{s} \alpha^{2} \Delta^{2}\right)^{2}\left(4 c_{R} \phi_{3}-c_{g} c_{s} \alpha^{2} \Delta^{2}\right)}>0 \\
\prod_{m t}^{\mathrm{MT} *}-\prod_{m}^{D *}-\prod_{t}^{D *}=\frac{2 \alpha^{2} c_{R}^{2} c_{g}^{2} c_{s}^{2} \Delta^{2} \phi_{1}^{2} \phi_{2}}{\left(2 c_{R} \phi_{2}-\alpha^{2} c_{g} c_{s} \Delta^{2}\right)\left(4 c_{R} \phi_{2}-\alpha^{2} c_{g} c_{s} \Delta^{2}\right)^{2}}>0 \\
\prod_{m r}^{\mathrm{MR} *} \prod_{m t}^{\mathrm{MT} *}=\frac{c_{R} c_{g}^{2} c_{s} \phi_{1}^{2}\left(8 c_{R} c_{s} \alpha-c_{s} \alpha^{2} \Delta^{2}-4 c_{R} \gamma^{2}\right)}{\left(4 c_{R} \phi_{3}-\alpha^{2} c_{g} c_{s} \Delta^{2}\right)\left(2 c_{R} \phi_{2}-c_{g} c_{s} \alpha^{2} \Delta^{2}\right)}>0
\end{gathered}
$$

The profit of the CLSC in the four models is $\prod_{c}^{\mathrm{MR} *}=\prod_{m r}^{\mathrm{MR} *}+\prod_{t}^{\mathrm{MR} *}, \quad \prod_{c}^{\mathrm{MT} *}=\prod_{m t}^{\mathrm{MT} *}+\prod_{r}^{\mathrm{MT} *}, \quad$ and $\prod_{c}^{D *}=\prod_{m}^{D *}+\prod_{r}^{D *}+\prod_{t}^{D *}, \quad$ since $\prod_{m r}^{\mathrm{MR} *}-\prod_{m}^{D *}-$ $\prod_{r}^{D *}>0, \quad \prod_{m t}^{\mathrm{MT} *}-\prod_{m}^{D *}-\prod_{t}^{D *}>0, \prod_{t}^{\mathrm{MR} *}>\prod_{t}^{D *}$, and $\prod_{r}^{\mathrm{MT} *}>\prod_{r}^{D *}$; hence $\prod_{c}^{\mathrm{MR} *}>\prod_{c}^{D *}$, and $\prod_{c}^{\mathrm{MT} *}>\prod_{c}^{D *}$. It also can be easily verified that

$$
\begin{aligned}
& \prod_{c}^{C *}-\prod_{c}^{\mathrm{MR} *}=\frac{2 \alpha^{2} c_{R}^{2} c_{g}^{2} c_{s}^{2} \Delta^{2} \phi_{1}^{2} \phi_{3}}{\left(2 c_{R} \phi_{3}-c_{g} c_{s} \alpha^{2} \Delta^{2}\right)\left(\alpha^{2} c_{g} c_{s} \Delta^{2}-4 c_{R} \phi_{3}\right)^{2}}>0, \\
& \prod_{c}^{C *}-\prod_{c}^{\mathrm{MT} *}=\frac{4 c_{R}^{3} c_{g}^{3} c_{s}\left(\gamma^{2}+2 \alpha c_{s}\right)^{2} \phi_{1}^{2}}{\left(2 c_{R} \phi_{3}-c_{g} c_{s} \alpha^{2} \Delta^{2}\right)\left(c_{g} c_{s} \alpha^{2} \Delta^{2}-2 c_{R} \phi_{2}\right)^{2}}>0 .
\end{aligned}
$$

\section{Proof of Proposition 9}

According to the previous conclusion $D^{D *}<D^{\mathrm{MT} *}<D^{\mathrm{MR} *}<D^{C *}$ and $\mathrm{CS}=\int_{(Q-D+\beta e+\gamma s / \alpha)}^{(Q+\beta e+\gamma s / \alpha)}\{\mathrm{Q}-\alpha p$ $+\beta e+\gamma s\} \mathrm{d} p=\left(D^{2} / 2 \alpha\right)$, we have $\mathrm{CS}^{D *}<\mathrm{CS}^{\mathrm{MT} *}<\mathrm{CS}^{\mathrm{MR} *}$ $<\mathrm{CS}^{\mathrm{C} *}$.

According to the previous conclusion $e^{D *}<e^{\mathrm{MT} *}<e^{\mathrm{MR} *}$ $<e^{C *}, D^{D *}<D^{\mathrm{MT} *}<D^{\mathrm{MR} *}<D^{C *}$, and $\mathrm{EI}=c_{e} e D$, we have $\mathrm{EI}^{D *}<\mathrm{EI}^{\mathrm{MT} *}<\mathrm{EI}^{\mathrm{MR} *}<\mathrm{EI}^{\mathrm{C} *}$.

According to the previous conclusion $\prod_{c}^{D *}<\prod_{c}^{\mathrm{MT} *}<\prod_{c}^{\mathrm{MR} *}<\prod_{c}^{\mathrm{C} *}$ and $\mathrm{SW}=\prod_{c}+\mathrm{CS}+\mathrm{EI}$, we have $\mathrm{SW}^{D *}<\mathrm{SW}^{\mathrm{MT} *}<\mathrm{SW}^{\mathrm{MR} *}<\mathrm{SW}^{\mathrm{C} *}$.

\section{Data Availability}

The data used to support the findings of this study are included within the article.

\section{Conflicts of Interest}

The authors declare that they have no conflicts of interest.

\section{Acknowledgments}

This research was supported by the National Natural Science Foundation of China (Grant no. 71771055), Key Projects of Natural Science of Anhui (Grant no. KJ2019A0519), Project of Natural Science of Provincial Platform (Grant no. 2020WLGH01), and Anhui Social Science Innovation and Development Project (Grant no. 2020CX057).

\section{References}

[1] S. S. Sana, "Price competition between green and non green products under corporate social responsible firm," Journal of Retailing and Consumer Services, vol. 55, Article ID 102118, 2020.

[2] H. Wang, X. Liu, N. Wang et al., "Key factors influencing public awareness of household solid waste recycling in urban areas of China: a case study," Resources, Conservation and Recycling, vol. 158, Article ID 104813, 2020.

[3] X.-X. Zheng, Z. Liu, K. W. Li, J. Huang, and J. Chen, "Cooperative game approaches to coordinating a three-echelon closed-loop supply chain with fairness concerns," 
International Journal of Production Economics, vol. 212, pp. 92-110, 2019.

[4] J. Cao, Y. Chen, B. Shi et al., "WEEE recycling in Zhejiang Province, China: generation, treatment, and public awareness," Journal of Cleaner Production, vol. 127, pp. 311-324, 2016.

[5] Y.-C. Tsao, V.-T. Linh, and J.-C. Lu, "Closed-loop supply chain network designs considering RFID adoption," Computers and Industrial Engineering, vol. 113, pp. 716-726, 2017.

[6] N. Wang, Q. He, and B. Jiang, "Hybrid closed-loop supply chains with competition in recycling and product markets," International Journal of Production Economics, vol. 217, pp. 246-258, 2019.

[7] P.-H. Tsai, G.-Y. Lin, Y.-L. Zheng, Y.-C. Chen, P.-Z. Chen, and Z.-C. Su, "Exploring the effect of Starbucks' green marketing on consumers' purchase decisions from consumers' perspective," Journal of Retailing and Consumer Services, vol. 56, Article ID 102162, 2020.

[8] N. M. Modak, N. Modak, S. Panda, and S. S. Sana, "Analyzing structure of two-echelon closed-loop supply chain for pricing, quality and recycling management," Journal of Cleaner Production, vol. 171, pp. 512-528, 2018.

[9] M. Ketelsen, M. Janssen, and U. Hamm, “Consumers' response to environmentally-friendly food packaging - a systematic review," Journal of Cleaner Production, vol. 254, Article ID 120123, 2020.

[10] A. K. Moser, "Consumers' purchasing decisions regarding environmentally friendly products: an empirical analysis of German consumers," Journal of Retailing and Consumer Services, vol. 31, pp. 389-397, 2016.

[11] X. Chen, X. Wang, and M. Zhou, "Firms' green R\&D cooperation behaviour in a supply chain: technological spillover, power and coordination," International Journal of Production Economics, vol. 218, pp. 118-134, 2019.

[12] N. M. Modak, D. K. Ghosh, S. Panda, and S. S. Sana, "Managing green house gas emission cost and pricing policies in a two-echelon supply chain," CIRP Journal of Manufacturing Science and Technology, vol. 20, pp. 1-11, 2018.

[13] J. Zhao, C. Wang, and L. Xu, "Decision for pricing, service, and recycling of closed-loop supply chains considering different remanufacturing roles and technology authorizations," Computers and Industrial Engineering, vol. 132, pp. 59-73, 2019.

[14] J. Hwang and J.-E. Chung, "What drives consumers to certain retailers for organic food purchase: the role of fit for consumers' retail store preference," Journal of Retailing and Consumer Services, vol. 47, pp. 293-306, 2019.

[15] T.-F. Kao and Y.-Z. Du, "A study on the influence of green advertising design and environmental emotion on advertising effect," Journal of Cleaner Production, vol. 242, Article ID 118294, 2020.

[16] Z. Hong and X. Guo, "Green product supply chain contracts considering environmental responsibilities," Omega, vol. 83, pp. 155-166, 2019.

[17] Z.-J. Ma, N. Zhang, Y. Dai, and S. Hu, "Managing channel profits of different cooperative models in closed-loop supply chains," Omega, vol. 59, pp. 251-262, 2016.

[18] J. Wei, Y. Wang, J. Zhao, and E. D. R. Santibanez Gonzalez, "Analyzing the performance of a two-period remanufacturing supply chain with dual collecting channels," Computers and Industrial Engineering, vol. 135, pp. 1188-1202, 2019.

[19] J. Wei, W. Chen, and G. Liu, "How manufacturer's integration strategies affect closed-loop supply chain performance,"
International Journal of Production Research, vol. 1, Article ID 1762016, 2020.

[20] C.-L. Shi, W. Geng, and J.-B. Sheu, "Integrating dual-channel closed-loop supply chains: forward, reverse or neither?" Journal of the Operational Research Society, vol. 1, Article ID 1745700, 2020.

[21] S. Swami and J. Shah, "Channel coordination in green supply chain management: the case of package size and shelf-space allocation," Technology Operation Management, vol. 2, no. 1, pp. 50-59, 2011.

[22] S. Kumar and P. Malegeant, "Strategic alliance in a closed-loop supply chain, a case of manufacturer and eco-non-profit organization," Technovation, vol. 26, no. 10, pp. 1127-1135, 2006.

[23] S. S. Sana, "A structural mathematical model on two echelon supply chain system," Annals of Operations Research, pp. 1-29, 2021.

[24] S. Panda, N. M. Modak, S. S. Sana, and M. Basu, "Pricing and replenishment policies in dual-channel supply chain under continuous unit cost decrease," Applied Mathematics and Computation, vol. 256, pp. 913-929, 2015.

[25] S. Saha, N. M. Modak, S. Panda, and S. S. Sana, "Managing a retailer's dual-channel supply chain under price- and delivery time-sensitive demand," Journal of Modelling in Management, vol. 13, no. 2, pp. 351-374, 2018.

[26] X.-M. Zhang, Q.-W. Li, Z. Liu, and C.-T. Chang, "Optimal pricing and remanufacturing mode in a closed-loop supply chain of WEEE under government fund policy," Computers and Industrial Engineering, Article ID 106951, 2020.

[27] Z. Liu, X.-X. Zheng, D.-F. Li, C.-N. Liao, and J.-B. Sheu, "A novel cooperative game-based method to coordinate a sustainable supply chain under psychological uncertainty in fairness concerns," Transportation Research Part E: Logistics and Transportation Review, vol. 147, Article ID 102237, 2021.

[28] K. Das and N. Rao Posinasetti, "Addressing environmental concerns in closed loop supply chain design and planning," International Journal of Production Economics, vol. 163, pp. 34-47, 2015.

[29] J. Gao, H. Han, L. Hou, and H. Wang, "Pricing and effort decisions in a closed-loop supply chain under different channel power structures," Journal of Cleaner Production, vol. 112, pp. 2043-2057, 2016.

[30] N. M. Modak, S. Panda, and S. S. Sana, "Three-echelon supply chain coordination considering duopolistic retailers with perfect quality products," International Journal of Production Economics, vol. 182, pp. 564-578, 2016.

[31] A. A. Taleizadeh, M. S. Jalali, S. S. Sana, Z. Huang, and J. Chevallier, "A game theoretic approach to optimal pricing of flights and passengers at congested airports," Journal of Modelling in Management, vol. 13, no. 2, pp. 434-454, 2018.

[32] L. Wang, G. G. Cai, A. A. Tsay, and A. J. Vakharia, "Design of the reverse channel for remanufacturing: must profit-maximization harm the environment?" Production and Operations Management, vol. 26, no. 8, pp. 1585-1603, 2017.

[33] M. Johari and S.-M. Hosseini-Motlagh, "Coordination of social welfare, collecting, recycling and pricing decisions in a competitive sustainable closed-loop supply chain: a case for lead-acid battery," Annals of Operations Research, 2019.

[34] Q. Wang, X. Hong, Y. Gong, and W. Chen, "Collusion or Not: the optimal choice of competing retailers in a closed-loop supply chain," International Journal of Production Economics, vol. 225, Article ID 107580, 2020.

[35] R. Qiu, Y. Wang, and T. Chen, "The intertemporal evolution model of enterprise R\&D cooperative network," Discrete 
Dynamics in Nature and Society, vol. 2019, Article ID 9241817, 12 pages, 2019.

[36] L. Xu, D. Liang, Z. Duan, and X. Xiao, "Stability analysis of $\mathrm{R} \& \mathrm{D}$ cooperation in a supply chain," Discrete Dynamics in Nature and Society, vol. 2015, Article ID 409286, 10 pages, 2015.

[37] H. Zhang, M. Wang, Z. Cheng, and L. Wan, "Technology-sharing strategy and incentive mechanism for $R \& D$ teams of manufacturing enterprises," Physica A: Statistical Mechanics and Its Applications, vol. 555, Article ID 124546, 2020.

[38] H.-Y. Zhang and D.-J. Hong, “"Manufacturer's R\&D investment strategy and pricng decisions in a decentralized supply chain," Discrete Dynamics in Nature and Society, vol. 2017, Article ID 9879874, 10 pages, 2017.

[39] F. Vendrell-Herrero, O. F. Bustinza, and M. Opazo-Basaez, "Information technologies and product-service innovation: the moderating role of service R\&D team structure," Journal of Business Research, 2020, In press.

[40] D.-M. Dai, X.-Y. Wu, and F.-S. Si, “The complexity analysis and control of time-delay OEM supply chain considering $\mathrm{R} \& \mathrm{D}$ efforts and marketing level," Mathematical Problems in Engineering, vol. 2020, Article ID 4746925, 12 pages, 2020.

[41] B. Huang, T.-L. Saaty, and Y.-Y. Li, "Collaborative R\&D and pricing policy of supply chain under the selection behavior of heterogeneous customer," Mathematical Problems in Engineering, vol. 2019, Article ID 2573142, 9 pages, 2019.

[42] A. Ranjan and J. K. Jha, "Pricing and coordination strategies of a dual-channel supply chain considering green quality and sales effort," Journal of Cleaner Production, vol. 218, pp. 409-424, 2019.

[43] Z. Wang and S. Liu, "Supply chain coordination under trade credit and quantity discount with sales effort effects," Mathematical Problems in Engineering, vol. 2018, p. 15, Article ID 2190236, 2018.

[44] Z. Basiri and J. Heydari, "A mathematical model for green supply chain coordination with substitutable products," Journal of Cleaner Production, vol. 145, pp. 232-249, 2017.

[45] M. Liu, B. Dan, S. Zhang, and S. Ma, "Information sharing in an e-tailing supply chain for fresh produce with freshnesskeeping effort and value-added service," European Journal of Operational Research, vol. 290, no. 2, pp. 572-584, 2021.

[46] G. Li, L. Li, and J. Sun, "Pricing and service effort strategy in a dual-channel supply chain with showrooming effect," Transportation Research Part E: Logistics and Transportation Review, vol. 126, pp. 32-48, 2019.

[47] H. Ding, L. Wang, and L. Zheng, "Collaborative mechanism on profit allotment and public health for a sustainable supply chain," European Journal of Operational Research, vol. 267, no. 2, pp. 478-495, 2018.

[48] Z. Yang, H. Chen, L. Du, C. Lin, and W. Lu, "How does alliance-based government-university-industry foster cleantech innovation in a green innovation ecosystem?" Journal of Cleaner Production, vol. 283, Article ID 124559, 2021.

[49] H. Wu, G. Li, S. Xiao, and H. Li, “Technology driven alliance for environmental and social responsibility in power supply chains," Journal of Cleaner Production, vol. 276, Article ID 123194, 2020.

[50] Z. Lin, S. Wang, and L. Yang, "Motivating innovation alliance's environmental performance through eco-innovation investment in a supply chain," Journal of Cleaner Production, vol. 269, Article ID 122361, 2020.

[51] S. Lechler, A. Canzaniello, and E. Hartmann, "Assessment sharing intra-industry strategic alliances: effects on sustainable supplier management within multi-tier supply chains,"
International Journal of Production Economics, vol. 217, pp. 64-77, 2019.

[52] A. A. Taleizadeh, V. R. Soleymanfar, and T.-M. Choi, "Optimal pricing and alliance strategy in a retailer-led supply chain with the return policy: a game theoretic analysis," Information Sciences, vol. 420, pp. 466-489, 2017.

[53] J. Choi, Z. Wang, B. Jiang, and T. Kim, "Coordination strategies in a three-echelon reverse supply chain for economic and social benefit," Applied Mathematical Modelling, vol. 49, pp. 599-611, 2017.

[54] X.-M. Zhang, Q.-W. Li, and G.-H. Qi, "Decision-making of a dual-channel closed-loop supply chain in the context government policy: a dynamic game theory," Discrete Dynamics in Nature and Society, vol. 2020, Article ID 2313698, 19 pages, 2020.

[55] X. Wu and Y. Zhou, "The optimal reverse channel choice under supply chain competition," European Journal of Operational Research, vol. 259, no. 1, pp. 63-66, 2017.

[56] J. Ding, W. Chen, and W. Wang, "Production and carbon emission reduction decisions for remanufacturing firms under carbon tax and take-back legislation," Computers \& Industrial Engineering, vol. 143, Article ID 106419, 2020.

[57] S. Panda, N. M. Modak, and L. E. Cárdenas-Barrón, "Coordinating a socially responsible closed-loop supply chain with product recycling," International Journal of Production Economics, vol. 188, pp. 11-21, 2017.

[58] Z. Liu, T. D. Anderson, and J. M. Cruz, "Consumer environmental awareness and competition in two-stage supply chains," European Journal of Operational Research, vol. 218, no. 3, pp. 602-613, 2012.

[59] K. Cao, P. He, and Z. Liu, "Production and pricing decisions in a dual-channel supply chain under remanufacturing subsidy policy and carbon tax policy," Journal of the Operational Research Society, vol. 71, no. 8, pp. 1199-1215, 2020.

[60] Z. Liu, J. Tang, B.-Y. Li, and Z. Wang, "Trade-off between remanufacturing and recycling of WEEE and the environmental implication under the Chinese fund policy," Journal of Cleaner Production, vol. 167, pp. 97-109, 2017. 